\title{
LA LENGUA ESPAÑOLA EN PANAMÁ
}

\author{
Antonio Quilis \\ y Matilde Graell Stanziola
}

0. Durante el verano de 1987, recorrimos la República de Panamá, haciendo las ençuestas previstas para el Atlas Lingiüstico de Hispanoamérica. Aplicamos el Cuestionario que, para la recogida de los materiales de esta obra, redactaron Manuel Alvar y Antonio Quilis ${ }^{1}$.

1. Los puntos encuestados, de oriente a occidente, fueron: Jaqué (Darién), Colón (Colón), Panamá (Panamá), Las Tablas (Los Santos), Santiago de Veraguas'(Veraguas). David (Chiriqui) y Changuinola (Bocas del Toro). En cada punto, entrevistamos a dos informantes: uno, con formación universitaria o similar, y otro, con estudios primarios (Panamá fue una excepción: tres informantes, dos de ellos universitarios) ${ }^{2}$. Además, recorrimos detenidamente el interior del pais y otros puntos de las provincias cuyas cabe-

1 Manuel Alvar y Antonio Quilis, Atlas Lingüístico de Hispanoamérica. Cuestionario, Madrid, Instituto de Cooperación Iberoamericana, 1984. Consta de 1.416 preguntas, distribuidas del siguiente modo: 758 para el léxico; 346 para fonética, y 312 para morfología y sintaxis.

2 Los informantes fueron los siguientes: en Jaqué: D. Isidro Segura Baloy, de 32 años, bachiller, con el primer año de la Facultad de Humanidades cursado; D. Amalio López Guarín, de 67 años, con instrucción primaria. En Colón: D. Alejandro Salazar Zorrilla, de 29 años, profesor de Derecho en la Universidad; D.* M." de los Ángeles Ortiz de Martínez, de 36 años, con instrucción primaria. En Panamá: D.* Judith Quesada de Velázquez, de 50 años, profesora de la Universidad; D. Aníbal Vallarino, de 39 años, abogado; D.* Dania Elvira Brooks, de 52 años, estudió hasta el tercer año de secundaria. En Las Tablas: D. Ab. diel Bolívar Hernández, de 42 años, licenciado en Derecho; D. Miguel González, bombero. de 42 años, con instrucción primaria. En Santiago de Veraguas: D." Eva Vannucchi Pini. lla, de 37 años, licenciada en Ciencias Biológicas; D." Andrea García de Vergara, de 49 años, con instrucción primaria. En David: D. Roberto Alfonso Guevara, de 29 años, profesor de Ciencias en la Universidad; D. Pantaleón Pérez Cruz, de 49 años, con instrucción primaria. En Changuinola: D. Rodolfo Williams, de 30 años, profesor de Enseñanza Secundaria; D.: Sol Ángel del Carmen Carrera, de 23 años, con instrucción secundaria. 
ceras estudiábamos, con el objeto de comprobar el área del voseo y su vigencia, de corroborar determinados fenómenos que aparecían en las encuestas e. incluso, de buscar otros que no estaban recogidos en nuestro Cuestionario.

2. En este trabajo, sólo pretendemos dar cuenta de los hechos más destacados que hemos encontrado y que, normalmente, no habian sido señalados para todo el territorio.

La bibliografía sobre el español de Panamá es escasa y, por otro lado, muy desigual: desde valiosos titulos hasta monografias que carecen. del más minimo rigor científico. En nuestro estudio, citaremos sólo aquellos trabajos que contienen alguna aportación para el conocimiento del tema que nos ocupa.

\section{Fonologia y fonética.}

3.1. En el vocalismo, podemos señalar:

3.1.1. Inestabilidad, no muy frecuente, de las vocales átonas: resurarse, entelegente, enteresado, sepoltura, en los informantes no universitarios ${ }^{3}$.

3.1.2. Tendencia antihiática, en todos los informantes, manifestada tanto en casos como [djáblo] diablo, [máis] maíz, etc., como [almóáda] almohada, [poéta] poeta, [gatęár] gatear. [máestro] maestro, que se convierten en las realizaciones, más abundantes, de [pantjón] panteón. [ipjár] hipear, [tjátro] teatro, [kwéte] cohete, [pwéta] poeta, [bjáta] beata, [golpjár] golpear. etc.

3.1.3. En los hablantes no universitarios se ha producido con relativa frecuencia la aparición de consonantes antihiáticas, en casos como tareda, vacido, sandiyal, etc., y también de vocales esvarabáticas o epentéticas : [tarámpa] trampa, [baráma] brama. [kalára] clara.

3.1.4. Es frecuente que en secuencias de vocales desiguales se pierda una de ellas, sobre todo, en los límites léxicos: [hometría] geometrí, [ká] que ha, [liso] le hizo, [tokurijó] te ocurrió, etc. El fenómeno aparece en todos los informantes.

3 Stanley L. Robe, en su obra The Spanish of rural Panamá (Berkeley and Los Angeles: University of California Press, 1960), ofrece abundantes ejemplos de inestabilidad de vocales átonas (págs. 32-36). 
3.1.5. Otros casos menos frecuentes han sido los siguientes: $a$ ) creación de un diptongo por analogía con otro existente en la misma palabra: [diferjénsja] diferencia ; $b$ ) metátesis de uno de los elementos del diptongo: [swiđá] ciudad.

3.1.6. En el caso de la secuencia tautosilábica /ué/, se han producido dos realizaciones, independientemente de su situación en la secuencia fónica y del informante: [wé], en el $67 \%$ de los casos, y [gwé], con /g/ oclusivo o fricativo, según el contorno, en el $33 \%$ restante ${ }^{4}$.

\subsection{Consonantes oclusivas.}

En las consonantes oclusivas, debemos mencionar los siguientes fenómenos :

3.2.1. Sonorización, en mayor o menor grado, de $/ \mathrm{p} /, / \mathrm{t} /, / \mathrm{k} /$ en posición intervocálica; sobre todo, es muy frecuente la de la velar, tanto en la posición indicada, como en inicial de palabra: [sabátos] zapatos, [lógos] locos, [gápa] capa, [páta] pata.

3.2.2. La secuencia consonántica /tl/ siempre se silabicó - tomando el término de Antonio de Nebrija - como tautosilábica, al igual que en el resto de Hispanoamérica y en Canarias: [á-tlas] atlas, [a-tláṇtiko] atlántico.

3.2.3. En Las Tablas, en Changuinola y en los informantes no universitarios de Jaqué y David, los fonemas $/ \mathrm{b} / \mathrm{y} / \mathrm{d} /$ se realizaron frecuentemente como oclusivos después de $/ 1 / \mathrm{y} / \mathrm{r} /:$ [ [kálbo] calvo, [bérde] verde. En los informantes no universitarios de Changuinola y Jaqué, también fue oclusivo /g/ después de /1/: [álgo] algo. Asimismo se realizaron, a veces, como oclu$\operatorname{sivos} / \mathrm{b} /, / \mathrm{d} /, / \mathrm{g} /$ después de $[\mathrm{r}$ ] en el informante no universitario de Santiago.

3.2.4. / $\mathrm{b} /$, en posición intervocálica, desaparece algunas veces: [tauxuéte] taburete. Se vocalizó, ocasionalmente, en la palabra [táưla] tabla.

3.2.5. El fonema /d/ intervocálico, en la terminación ado, se pierde generalmente en todos los hablantes, aunque, a veces, lo repongan. En la terminación $-a d a$, suele perderse en los estratos sociales no cultos ${ }^{5}$.

4 La misma alternancia señala Robe, op. cit., pág. 41.

s Véase también Robe, op. cit., págs. 42-43. 
3.2.6. El fonema $/ \mathrm{g} /$, después de pausa, se realizó algunas veces como fricativo. En contacto con una vocal labiovelar, desaparece ocasionalmente: [áwa] agua.

3.2.7. Los fonemas oclusivos, en posición postnuclear o implosiva, presentan en español, a causa de su neutralización, numerosas realizaciones. El habla que estudiamos no podía ser una excepción. En el mencionado contorno, tienen el siguiente comportamiento, independientemente del estrato sociocultural de los hablantes:

a) $[-p]$ : en orden decreciente de frecuencia, presenta las siguientes realizaciones: $1 .^{\mathrm{a}}:[-\mathrm{p}]$ : [kápsula] cápsula $; 2 .^{\mathrm{a}}:[\mathrm{k}]:\left[\overline{\mathrm{r}}\right.$ aktár] raptar; $3 .^{\mathrm{a}}$ : [-b]: [kábsula] cápsula; $.^{\mathrm{a}}:$ [u] : [káusula] cápsula, y, por último, [-p]

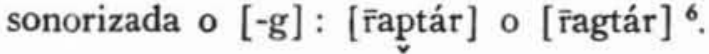

b) $[-\mathrm{t}]$ : en orden decreciente de frecuencia, presenta las siguientes realizaciones: $1 .^{\mathrm{a}}:[-\mathrm{d}]$ : [aridmétika] aritmética; $2 .^{\mathrm{a}}:[-\mathrm{t}]$ : [aritmétika] y $[-\varnothing]$ : [arimétika] ; $3 .^{\mathrm{a}}:$ [đ] fricativa: [ariđmétika]; $4 .^{\mathrm{a}}:[-\mathrm{s}]:$ [rísmo] ritmo, [arismétika].

c) $[-\mathrm{k}]$ : en orden decreciente de frecuencia, presenta las siguientes realizaciones: $1 .^{\mathrm{a}}:[-\mathrm{g}]:\left[\right.$ defégto] defecto $; 2 .^{\mathrm{a}}:[-\mathrm{k}]:\left[\right.$ leksjón] lección; $3 .^{\mathrm{a}}$ : $[-\mathrm{p}]:$ [eruptár] eructar; $4^{\mathrm{a}}:[-\varnothing]$ : [dotór] doctor ?

d) [-b] : las realizaciones que aparecieron, en orden decreciente de frecuencia, fueron las siguientes: $1 .^{\mathrm{a}}:[-\mathrm{p}]:\left[\right.$ apsorter] absorber; $2 .^{\mathrm{a}}:[-\mathrm{b}]$ : [obserbár] observar; $3 .^{\mathrm{a}}:[-\varnothing]:$ [osékjo] obsequio; $4 .^{\mathrm{a}}:[-\mathrm{b}]$ fricativa: [absorbér], y [-k]: [aksorbér] absorber; $5 .^{\mathrm{a}}:[-\mathrm{u}]$ ] : [oussékjo] obsequio, [ouxserbár] observar.

e) [-d] : en orden decreciente de frecuencia, presenta las siguientes realizaciones: $1 .^{\mathrm{a}}:$ [-d] : [admisjón] admisión; $2 .^{\mathrm{a}}:$ [-đ] fricativa: [ađmirár] admirar; $3 .^{\mathrm{a}}:[-\mathrm{t}]$ : [ [rét] red; $4 .^{\mathrm{a}}$ : otras realizaciones ocasionales: [-h] : [ahmisjón] admisión; [-d̆] ensordecida: [aḑmitír] admitir; [-r] : [ataúr], o [-1] : [ataúl] ataud. En posición final de palabra, desaparece casi siempre.

f) $[-g]$ : realizaciones en orden decreciente de frecuencia: $1 .^{a}$ : su conservación como oclusiva, $[-\mathrm{g}]$ : [ignoránte] ignorante; $2 .^{\mathrm{a}}:[-\varnothing]$ : [manésja] magnesia; $3 .^{\mathrm{a}}:[-\mathrm{g}]$ fricativa o $[-\mathrm{k}]$ : [ignoránte] o [iknoránte].

- Casos similares registra Robe, op. cit., pág. 44.

7 Casos similares registra Robe, op. cit., pág. 45. 


\subsection{Consonantes fricativas.}

\subsubsection{Fonema /f/.}

Nuestros informantes no universitarios lo realizaron siempre como bilabial, con excepción del de Changuinola. En los universitarios, predomina también el alófono bilabial; en tres de ellos, alternó con [f] ${ }^{8}$.

En el habla rural de las provincias centrales, es frecuente la realización [h] de [f] seguida de [we], [wi], tanto en posición interior de palabra como en inicial; son casos como: [hwí] fui, [hwéron] fueron, [hwérsa] fuerza, [hwét:e] fuerte, [ahwéra] afuera. En las encuestas sistemáticas (las realizadas con el Cuestionario), no registramos el fenómeno ${ }^{9}$.

\subsubsection{Fonema $/ \mathrm{s} /$.}

El fonema /s/ es en Panamá muy polimórfico. Hemos inventariado los siguientes alófonos:

[s1] : alófono ápicoalveolar; el más antiguo, si atendemos a la cronología de la evolución de este fonema; fue localizado en Jaqué. El comienzo de su frecuencia tiene un valor medio de $2.560 \mathrm{~Hz}$.

En la figura 1, está reproducido el sonograma de una [s] ápicoalveolar del punto mencionado, en la secuencia Una rosa. La frecuencia de su fricación comienza a los $2.590 \mathrm{~Hz}$.

[s2] : alófono ápicodentoalveolar; en los informantes cultos de Jaqué y Las Tablas. El comienzo de su frecuencia tiene un valor medio de $3.450 \mathrm{~Hz}$.

[s3]: alófono predorsoalveolar; localizado en los informantes cultos de Colón y Changuinola, y en todos los de Santiago y David ${ }^{10}$. El valor medio del comienzo de su frecuencia es de $4.160 \mathrm{~Hz}$.

8 Según Robe, op. cit., pág. 45, entre los hablantes rurales y los que no han estado escolarizados se produce alternancia entre las realizaciones labiodental y bilabial de /f/.

- Véase Matilde Graell, «Comportamiento de los fonemas fricativos en el español hablado en Panamám, La Antigua (Universidad Santa Marfa La Antigua, Panamá), 23, 1984, págs. 52-69.

Robe, op. cit., pág. 45, señala también casos de [xwé] por [fue].

La forma fierro 'hierro' es general en Panamá.

10 Este es el único alófono que señala Robe en su estudio (op. cit., pág. 46). 
[s4] : alófono predorsodentoalveolar; es el más frecuente en el país; presenta dos variantes:

a) Una de ellas, con predominio de la constricción alveolar ; fue recogida en Panamá, en los informantes universitarios, y en el no universitario de Jaqué. El comienzo de su frecuencia tiene un valor medio de $4.600 \mathrm{~Hz}$.

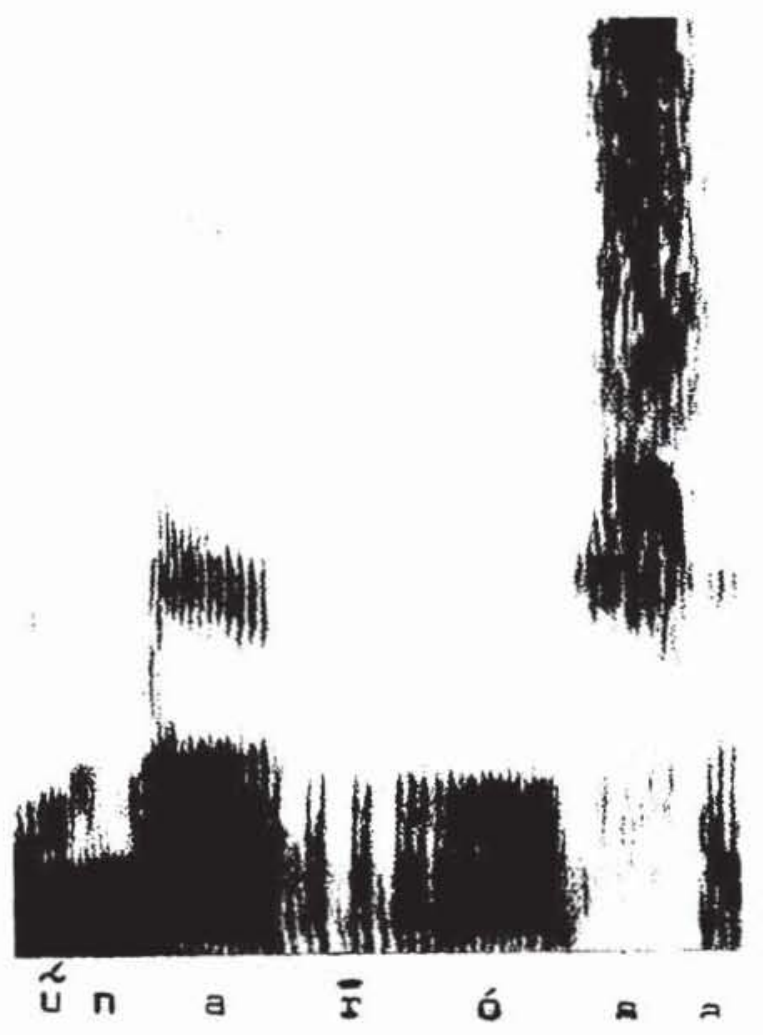

Fig. 1.-Sonograma de una [s] ápicoalveolar.

En la figura 2, aparece el sonograma de esta variante, perteneciente a la secuencia Dos casas. Su frecuencia de fricación comienza a los $4.200 \mathrm{~Hz}$.

b) En la otra variante, predomina la constricción dental. Apareció en los informantes no universitarios de Colón, Panamá, Las Tablas y David, y en el universitario de Santiago. El comienzo de su frecuencia es, lógicamente, más alto: tiene un valor medio de $5.100 \mathrm{~Hz}$. 
[s5] : alófono predorsointerdental, también con dos variantes:

a) Una es la estridente. Su articulación es la siguiente: lengua convexa, con su corona apoyada en la cara interior de los incisivos inferiores; la constricción se realiza entre el predorso y la zona dentoalveolar; como la corriente de aire, después del lugar de articulación, choca contra la harrera suplementaria de los incisivos superiores, el alófono [s] resultante es estridente. Lo recogimos en el informante culto de Panamá, alternando con el alófono predorsodentoalveolar ${ }^{11}$, y en el no universitario de Changuinola. El valor medio del comienzo de su frecuencia es de $4.720 \mathrm{~Hz}$.
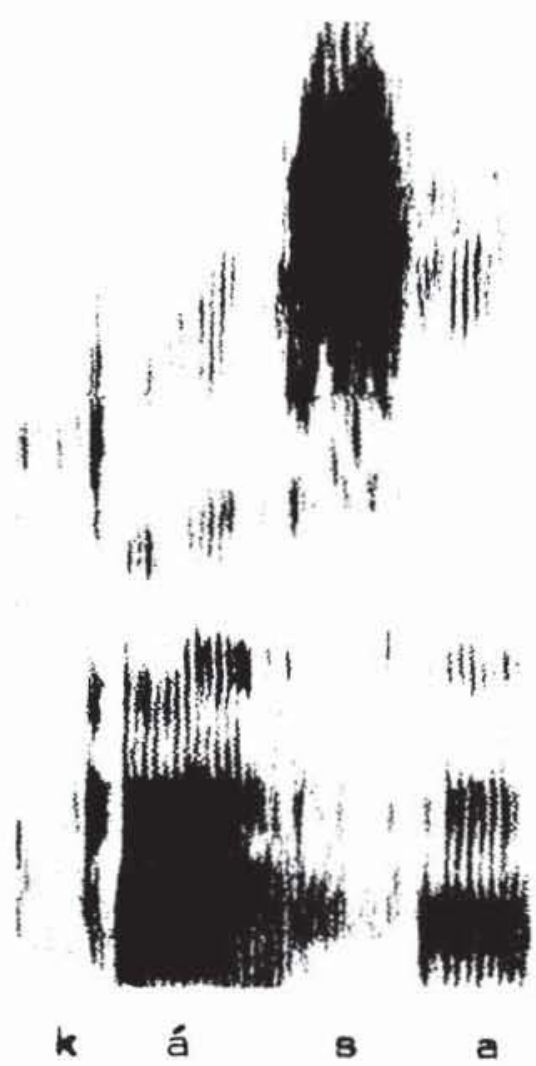

Fig. 2.-Sonograma de una [s] predorsodentoalveolar.

b) La otra variante es la mate, $[\theta]$. La misma articulación que para la estridente, con la diferencia de que la constricción se realiza entre el predorso

11 En este informante, el alofono predorsodentoalveolar tiene un porcentaje de realización del $83 \%$; el $17 \%$ restante corresponde al predorsointerdental. 
lingual y los incisivos superiores; al no existir ninguna barrera posterior al lugar de articulación, el alófono resultante es mate, de timbre parecido al del alófono interdental, $[\theta]$, del dialecto castellano. Lo recogimos en los siguientes puntos, y con la frecuencia que indicamos: ocasionalmente, en los informantes no universitarios de Jaqué, Las Tablas y Changuinola, y en el universitario de David. En el informante no universitario de Colón, supone un porcentaje del 20,8\% del total de las realizaciones de /s/ (el 8,5\% de este porcentaje corresponde a una realización plenamente interdental, $[\theta])$; en el no culto de Panamá, representa el 22,6\% del total de alófonos de /s/ (el $7,34 \%$ de este porcentaje es del interdental $[\theta])$; en la informante culta de Panamá, supone el $4 \%$ del total de alófonos de /s/. El valor medio del comienzo de frecuencia es de $4.500 \mathrm{~Hz}$.

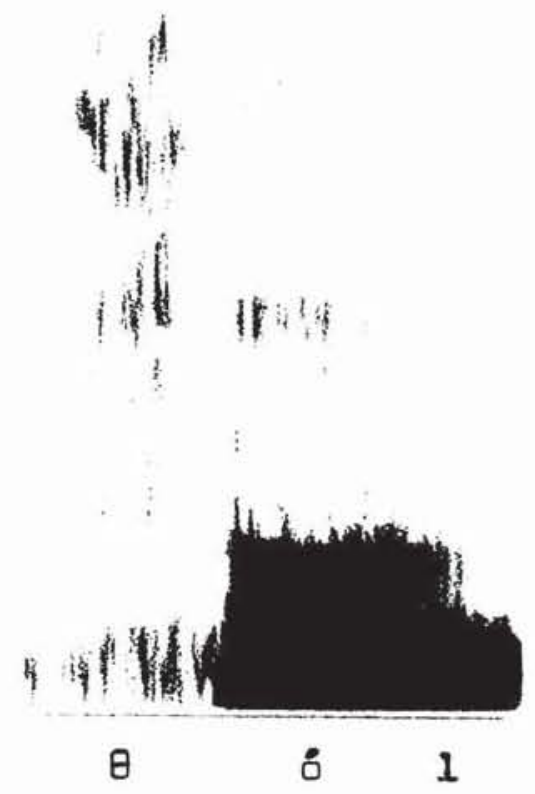

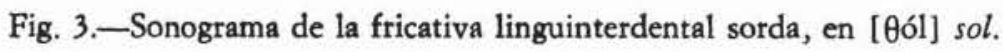

$Y$ por último, $[\theta]$ : alófono interdental, mate, al que ya nos hemos referido en el párrafo anterior.

En la figura 3 aparece el sonograma de esta realización interdental, en [ $\theta$ ól] sol. 
En resumen, los distintos alófonos de /s/, por puntos de encuesta, aparecen en el cuadro siguiente:

\begin{tabular}{|c|c|c|c|c|c|c|c|}
\hline & s1 & s2 & s3 & s4 & s5 & $\theta$ & $\theta$ \\
\hline Jaqué $\ldots \ldots \ldots \ldots$ & * & * & & * & & * & \\
\hline Colón ... ... ..... & & & * & * & & * & * \\
\hline Panamá ... ... ... & & & & * & * & * & * \\
\hline Las Tablas $\ldots \ldots$ & & * & & * & & * & \\
\hline Santiago .......... & & & * & * & & & \\
\hline $\begin{array}{lllll}\text { David } & \ldots & \ldots & \ldots\end{array}$ & & & * & * & & * & \\
\hline Changuinola ....... & & & * & & * & * & \\
\hline
\end{tabular}

3.3.2.1. Fonema $/ \mathrm{s} /$ en posición postnuclear o implosiva. Sus porcentajes de mantenimiento ( $s$, en los cuadros que vienen a continuación), de aspiración faríngea (algunas veces laríngea; $h$, en los cuadros) y de desaparición $(\varnothing$, en los cuadros), según siga pausa (\#) $\mathbf{u}$ otra consonante, son los siguientes:

3.3.2.1.1. Jaqué: informante no universitario:

\begin{tabular}{|c|c|c|c|c|c|c|c|c|c|c|c|c|c|}
\hline & -s\# & sp & st & sk & sb & sd & sg & sf & sy & sm & sn & sl & Total \\
\hline s ...... & 22 & 2,5 & 8,6 & 5,5 & & & & 0,3 & 0,3 & 0,7 & 0,7 & 0,3 & 40,9 \\
\hline h...... & 1 & 4,3 & 7,6 & 3,6 & 0,3 & & 0,3 & & & 0,7 & 0,3 & 0,3 & 18,4 \\
\hline$\emptyset \ldots \ldots$ & 26,3 & 1 & 0,7 & 1,4 & 0,7 & 2,1 & 2,1 & 2,1 & & 1,4 & 0,7 & 1,8 & 40,3 \\
\hline
\end{tabular}

3.3.2.1.2. Jaqué: informante universitario:

\begin{tabular}{|c|c|c|c|c|c|c|c|c|c|c|c|c|c|}
\hline & -s\# & sp & st & sk & sb & sd & sg & sf & sy & sm & sn & sl & Total \\
\hline s ..... & 34 & 3 & 4 & 5,5 & 1,5 & 0,4 & 1,2 & & 0,4 & 2 & 2 & 2 & 56 \\
\hline h $\ldots \ldots$ & 3,6 & 3,6 & 8,3 & 6 & 0,4 & 0,8 & 0,4 & & & 0,4 & 0,4 & & 23,9 \\
\hline$\emptyset \ldots \ldots$ & 14 & 0,4 & 0,4 & 1,2 & 0,4 & 0,8 & 0,4 & 1,2 & 0,4 & 0,4 & & 0,4 & 20 \\
\hline
\end{tabular}

3.3.2.1.3. Colón: informante no universitario:

\begin{tabular}{|c|c|c|c|c|c|c|c|c|c|c|c|c|c|}
\hline & -s\# & sp & st & sk & sb & sd & $\mathbf{s g}$ & sf & sy & $\mathrm{sm}$ & sn & sl & TotaL \\
\hline$s \ldots \ldots$ & 17 & 2 & 6 & 1 & 0,5 & 0,3 & & & & 2 & 0,4 & 1 & 25,2 \\
\hline h...... & 11 & 5,5 & 8 & 9 & 0,8 & 0,4 & 0,4 & & & 0,7 & 0,7 & & 36,5 \\
\hline$\varnothing \ldots \ldots$ & 30 & 0,3 & 1 & 1 & 0,4 & 0,7 & 1,3 & 1 & 0,7 & 0,3 & 0,4 & 0,7 & 37,8 \\
\hline
\end{tabular}


3.3.2.1.4. Colón: informante universitario:

\begin{tabular}{|c|c|c|c|c|c|c|c|c|c|c|c|c|c|}
\hline & -s\# & sp & st & sk & sb & sd & sg & sf & sy & $\mathrm{sm}$ & sn & sl & Total \\
\hline s ...... & 10 & 4 & 8,7 & 7,6 & 1,5 & 1,1 & 1,9 & 0,4 & & 2,3 & 0,7 & 2,3 & 40,5 \\
\hline h...... & & 2,6 & 5 & 1,3 & 0,3 & 0,4 & 0,3 & & & 0,3 & 0,3 & & 10,5 \\
\hline$\emptyset \ldots \ldots$ & 40 & 0,8 & 0,4 & 2,3 & 0,4 & 1,3 & 0,7 & 0,7 & & 1,3 & 0,4 & 0,4 & 48,7 \\
\hline
\end{tabular}

3.3.2.1.5. Panamá: informante universitaria:

\begin{tabular}{|c|c|c|c|c|c|c|c|c|c|c|c|c|c|}
\hline & -s\# & $\mathrm{sp}$ & st & sk & sb & sd & $\mathrm{sg}$ & sf & sy & $\mathrm{sm}$ & sn & $\mathrm{sl}$ & Total. \\
\hline s ...... & 58 & & 3 & 0,2 & & & & & & & 0,4 & 0,2 & 61,8 \\
\hline h $\ldots \ldots$ & 2,2 & 4,4 & 4,4 & 4 & & 1 & 0,2 & & 0,5 & 1,4 & 1,2 & 0,4 & 19,7 \\
\hline$\varnothing \ldots \ldots$ & 8,4 & 0,4 & 1,5 & 0,8 & 0,8 & 0,6 & 1 & 3 & 0,4 & 0,6 & 0,2 & 0,8 & 18,5 \\
\hline
\end{tabular}

3.3.2.1.6. Panamá: informante no universitaria:

\begin{tabular}{|c|c|c|c|c|c|c|c|c|c|c|c|c|c|}
\hline & $\cdot s \#$ & sp & st & sk & sb & sd & sg & sf & sy & $\mathrm{sm}$ & sn & sl & Total. \\
\hline $8 \ldots \ldots$ & 19 & 0,8 & 1,8 & 0,4 & & 0,8 & 0,4 & 0,4 & & 1,2 & 0,4 & 0,4 & 25,8 \\
\hline h ...... & 3 & 6,3 & 13 & 12 & 1,4 & 1,7 & 0,8 & & 1,2 & 1,2 & 0,8 & 0,8 & 42,2 \\
\hline Ø...... & 26 & & 0,4 & 0,8 & 0,4 & 0,8 & 0,8 & 1,2 & & 1,2 & 0,4 & & 32 \\
\hline
\end{tabular}

3.3.2.1.7. Panamá: informante universitario:

\begin{tabular}{|c|c|c|c|c|c|c|c|c|c|c|c|c|c|}
\hline & -s\# & sp & st & sk & $\mathrm{sb}$ & sd & sg & sf & sy & $\mathrm{sm}$ & sn & sl & Total \\
\hline $8 \ldots \ldots$ & 12 & & 2,8 & 0,7 & 0,4 & & & & & & 0,4 & & 16,3 \\
\hline h....... & 17 & 7,6 & 13 & 10 & 0,8 & 1,2 & 1,8 & & 0,8 & 1,2 & 2,4 & 2 & 57,8 \\
\hline$\varnothing \ldots \ldots$ & 20 & & & 0,4 & & 0,4 & 0,8 & 2 & 0,4 & 0,8 & 0,4 & & 25,2 \\
\hline
\end{tabular}

3.3.2.1.7. Las Tablas: informante no universitario:

\begin{tabular}{|c|c|c|c|c|c|c|c|c|c|c|c|c|c|}
\hline & -s\# & sp & st & sk & sb & sd & $\mathrm{sg}$ & sf & sy & $\mathrm{sm}$ & sn & sl & Total \\
\hline s ...... & 19 & 7,7 & 3,5 & 2 & 0,4 & & & & & 0,4 & & & 33 \\
\hline h...... & 7,4 & & 11 & 9,6 & & 0,4 & 0,8 & & & 1,7 & 0,4 & 0,8 & 32 \\
\hline$\emptyset \ldots \ldots$ & 24 & 0,4 & 1,7 & 0,4 & 0,4 & 0,8 & 2 & 0,8 & 1,3 & 1,3 & 0,4 & 1,3 & 34,8 \\
\hline
\end{tabular}


3.3.2.1.8. Las Tablas: informante universitario:

\begin{tabular}{|c|c|c|c|c|c|c|c|c|c|c|c|c|c|}
\hline & -s\# & sp & st & sk & $\mathrm{sb}$ & sd & sg & sf & sy & $\mathrm{sm}$ & sn & sl & Total \\
\hline s ..... & 32 & 0,7 & 4,6 & 2,9 & & & 0,4 & 0,4 & & 0,4 & 0,8 & 0,8 & 43 \\
\hline h ....... & 3,8 & 5,5 & 9,7 & 8,9 & & 0,4 & 0,4 & & 0,4 & 2,1 & 2,1 & 0,8 & 34,1 \\
\hline$\emptyset \ldots \ldots$ & 14 & 0,6 & 0,8 & & 1,2 & 0,8 & 2,1 & 2,1 & & 0,4 & & 0,8 & 22,8 \\
\hline
\end{tabular}

3.3.2.1.9. Santiago: informante no universitario:

\begin{tabular}{|c|c|c|c|c|c|c|c|c|c|c|c|c|c|}
\hline & -s\# & $\mathrm{sp}$ & st & sk & $s b$ & sd & sg & sf & sy & $\mathrm{sm}$ & sn & sl & Total \\
\hline $\mathrm{s} \ldots \ldots$ & 20 & & 3,3 & 0,4 & & & & 1,8 & & 0,4 & & & 25,9 \\
\hline h...... & 6 & 6 & 9 & 10 & 2,7 & 0,4 & 1,8 & & & 2,6 & 1,5 & 0,4 & 40,4 \\
\hline$\varnothing \ldots \ldots$ & 24 & 3 & 0,4 & 0,8 & & 0,8 & 1,1 & & 1,1 & 1,5 & & 0,8 & 33,56 \\
\hline
\end{tabular}

3.3.2.1.10. Santiago: informante universitario:

\begin{tabular}{|c|c|c|c|c|c|c|c|c|c|c|c|c|c|}
\hline & -s\# & $\mathrm{sp}$ & st & sk & sb & sd & sg & sf & sy & $\mathrm{sm}$ & sn & sl & Total \\
\hline & 32 & 6,3 & 9,5 & 7 & 1,2 & 0,3 & 2,4 & & 0,3 & 2,7 & 1,6 & 1,6 & 64,8 \\
\hline h ...... & 2,7 & 2 & 7,5 & 3,5 & & & 1,6 & & & 1,2 & 1,2 & 0,8 & 20,5 \\
\hline$\varnothing \ldots \ldots$ & 11 & 0,3 & 0,3 & & & 1,6 & 0,3 & & 0,3 & & & 0,3 & 14,1 \\
\hline
\end{tabular}

3.3.2.1.11. David: informante no universitario:

\begin{tabular}{|c|c|c|c|c|c|c|c|c|c|c|c|c|c|}
\hline & s" \# & sp & st & sk & sb & sd & sg & sf & sy & $\mathrm{sm}$ & sn & sl & Total \\
\hline$s \ldots \ldots$ & 32 & 4,3 & 9,2 & 3,4 & 0,8 & 0,8 & & & & 1,3 & 1,3 & 1,3 & 54,3 \\
\hline h...... & 3 & 1,3 & 11 & 6 & & 0,4 & 2 & & & 1,1 & 0,4 & 1,3 & 26,5 \\
\hline$\varnothing \ldots \ldots$ & 8,5 & 0,8 & 2,2 & & 0,8 & 0,8 & 2,2 & 2,6 & & 0,4 & 0,4 & 0,4 & 19,1 \\
\hline
\end{tabular}

3.3.2.1.12. David: informante universitario:

\begin{tabular}{|c|c|c|c|c|c|c|c|c|c|c|c|c|c|}
\hline & -s\# & sp & st & sk & sb & sd & sg & sf & sy & sm & sn & sl & Total \\
\hline$s \ldots \ldots$ & 43 & 4 & 11 & 6,5 & 1 & 1,5 & 1,5 & 1 & & 2,5 & 2 & 1 & 76 \\
\hline h ...... & 1 & 3,4 & 6 & 4 & 0,5 & 0,5 & 0,5 & & & & 0,5 & & 16,4 \\
\hline$\varnothing \ldots \ldots$ & 5 & & 0,5 & 0,5 & & 0,5 & 1 & & & & & & 7,5 \\
\hline
\end{tabular}


3.3.2.1.13. Changuinola: informante no universitario:

\begin{tabular}{|c|c|c|c|c|c|c|c|c|c|c|c|c|c|}
\hline & -s\# & sp & st & sk & sb & sd & sg & sf & sy & sm & sn & sl & TotaL \\
\hline s $\ldots \ldots$ & 17 & 3,4 & 9,5 & 5 & & 1,1 & 0,7 & 0,3 & & 0,7 & & 0,7 & 38,4 \\
\hline h...... & 18 & 4,5 & 5,6 & 3,8 & 0,7 & 0,7 & 0,7 & & & 1,1 & 0,7 & 0,7 & 36,54 \\
\hline$\varnothing \ldots \ldots$ & 13 & 0,7 & 1,1 & 1,1 & & 0,3 & 1,5 & 1,1 & 2 & 2 & 0,3 & 0,7 & 23,88 \\
\hline
\end{tabular}

3.3.2.1.14. Changuinola: informante universitario:

\begin{tabular}{|c|c|c|c|c|c|c|c|c|c|c|c|c|c|}
\hline & -s\# & sp & st & sk & sb & sd & $\mathrm{sg}$ & sf & sy & sm & sn & sl & Total \\
\hline s $\ldots \ldots$ & 27 & 4,7 & 8,2 & 5,7 & 0,4 & 0,4 & 1,6 & 0,4 & 0,4 & 2,4 & 0,8 & 0,8 & 52,8 \\
\hline h...... & 3 & 3,3 & 2,7 & 7 & & 0,8 & 0,4 & & & 1,6 & 0,4 & 1,2 & 20,5 \\
\hline$\emptyset \ldots \ldots$ & 19 & 1,8 & & 0,4 & 0,8 & 1,6 & & 1,2 & 0,4 & & 0,8 & & 26 \\
\hline
\end{tabular}

Como puede verse por los cuadros anteriores, en general, los informantes con instrucción superior conservan, o reponen, más veces que los demás la consonante [-s]. Los no universitarios la aspiran o pierden más frecuentemente ${ }^{12}$.

\subsubsection{Fonema $/ y /$.}

Los alófonos del fonema /y/ tienen en Pananá prácticamente la misma distribución que en el español general, con excepción de la posición inicial, después de pausa, donde frecuentemente aparece la realización fricativa, $[y]$.

En el cuadro que ofrecemos a continuación damos las realizaciones de $/ \mathrm{y} /$ en posición prenuclear, después de pausa (\#) o de consonante (C); $u$, después de la inicial del topónimo ${ }^{13}$, indica que se trata del informante universitario. Cuando sólo aparece una inicial (en J y en P, por ejemplo) es porque todos los informantes coinciden el mismo tipo de alófono.

12 Robe, op. cit., págs. 45-47, sólo recoge casos de aspiración.

Henrietta J. Cedergren registró también, en la ciudad de Panamá, las mismas tres rea. lizaciones de /-s/, señaladas más arriba (véase su trabajo: «En torno a la variación de la $\mathrm{S}$ final de sflaba en Panamá: análisis cuantitativow. En Corrientes actuales en la dialectologia del Caribe hispánico, editadas por H. López Morales. Editorial Universitaria, Universidad de Puerto Rico, 1978, págs. 35-50).

${ }_{13}$ Las iniciales de las poblaciones son las siguientes: J: Jaqué; C: Colón; P: Panamá; T: Las Tablas; S: Santiago; D: David; Ch: Changuinola. 
Los alófonos son los siguientes:

- $[\mathrm{y}]$ : fricativo sonoro ${ }^{14}$;

- $[\hat{y}]$ : africado sonoro, prácticamente sin fricación; es una oclusiva palatal;

- [₹]: africado sonoro;

- [ž $]$ : fricativo sonoro.

Los números indican: 1 : articulación alveoloprepalatal; 2 : articulación prepalatal; 3 : articulación mediopalatal.

\begin{tabular}{|c|c|c|c|c|c|c|c|c|}
\hline & $\# y-$ & $\# \hat{\mathrm{y}}-$ & $\# \frac{8}{2}$ & $\#$ ž- & C y- & C $\hat{y}$ - & $C$ \&- & $C \grave{z}$ \\
\hline J ........ & 3 & 3 & 3 & 3 & & 3 & & \\
\hline $\begin{array}{lll}C & \ldots & \ldots\end{array}$ & 3 & 2 & 2 & 2 & 3 & 2 & & 3 \\
\hline $\mathrm{Cu} \ldots \ldots$ & & 2 & 2 & & 3 & 2 & & 3 \\
\hline $\begin{array}{lll}P & \ldots & \ldots\end{array}$ & 3 & 2 & & & 2 & 2 & & \\
\hline $\mathrm{T} \ldots \ldots$ & 3 & 3 & 3 & 2 & & 3 & & 2 \\
\hline Tu ....... & 3 & 3 & & & 3 & 3 & & 2 \\
\hline $\begin{array}{llll}S & \ldots & \ldots\end{array}$ & & 3 & 1 & & 3 & & 1 & \\
\hline Su ... .... & & 3 & 1 & & & 3 & 1 & \\
\hline $\mathrm{D} \ldots \ldots$ & & 3 & & 2 & & 3 & & \\
\hline $\mathrm{Du} \ldots \ldots$ & & 3 & 3 & 3 & 3 & 3 & & 3 \\
\hline $\mathrm{Ch} \ldots \ldots$ & & 1 & 1 & 1 & & 1 & 1 & \\
\hline Chu ....... & 2 & 1 & & & 2 & 1 & 1 & \\
\hline
\end{tabular}

En el cuadro siguiente, damos los valores de $/ y /$ en posición intervocálica :

\begin{tabular}{|c|c|c|c|c|}
\hline & $-\mathrm{y}$ - & $-\hat{\mathrm{y}}$ - & $-\dot{z}-$ & $-2-$ \\
\hline $\begin{array}{llllll}\mathbf{J} & \ldots & \ldots & \ldots & \ldots\end{array}$ & 3 & 3 & 3 & 3 \\
\hline $\begin{array}{lllll}\mathrm{Ju} & \ldots & \ldots & \ldots\end{array}$ & 3 & & 3 & 3 \\
\hline $\mathrm{C} \ldots \ldots \ldots$ & & 2 & 2 & 2 \\
\hline $\begin{array}{lllll}\mathrm{Cu} & \ldots & \ldots & \ldots\end{array}$ & 3 & 2 & & 2 \\
\hline $\begin{array}{lllll}\mathrm{P} u & \ldots & \ldots & \ldots\end{array}$ & 3 & & & 2 \\
\hline $\mathbf{P} \ldots \ldots \ldots \ldots$ & 3 & 3 & & \\
\hline $\begin{array}{lllll}\mathrm{Pu} & \ldots & \ldots & \ldots\end{array}$ & 3 & & & \\
\hline $\mathrm{T} \ldots \ldots \ldots \ldots$ & 3 & & 2 & 3 \\
\hline $\begin{array}{ccccc}\mathrm{Tu} & \ldots & \ldots & \ldots\end{array}$ & 3 & 3 & 2 & \\
\hline 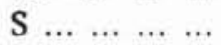 & 3 & & 1 & 1 \\
\hline $\mathrm{D} \ldots \ldots \ldots \ldots$ & 3 & & 2 & 2 \\
\hline $\begin{array}{lllll}\mathrm{Du} & \ldots & \ldots & \ldots\end{array}$ & 3 & & 3 & 3 \\
\hline $\begin{array}{lllll}C h & \ldots & \ldots & \ldots\end{array}$ & 3 & & 2 & 2 \\
\hline $\begin{array}{ccccc}\text { Chu } & \ldots & \ldots & \ldots\end{array}$ & 3 & & 2 & \\
\hline
\end{tabular}

14 Nosotros no hemos encontrado el alofono [j] - «voiced palatal glide» o «semiconsonant», que señala Robe, op. cit., pág. 56. Además de éste, señala el africado sonoro y el fricativo palatal [ž] . 
Como se ve, las articulaciones de $[-y-]$ son siempre mediopalatales, pero el resto de los alófonos tienen distintos lugares de articulación.

\subsubsection{Fonema $/ \mathbf{x} /$.}

Hemos encontrado en la República de Panamá tres tipos de alófonos de $/ \mathbf{x} /$ : el fricativo faringeo, que es el más frecuente, y el que poseen todos los informantes: le sigue el laríngeo, alternando con aquél, y, por último, el velofaríngeo. Frecuentemente aparecen dos, y, a veces, los tres alófonos en un mismo informante. No encontramos el alófono velar que, como única solución, señaló Robe en su trabajo ${ }^{15}$.

Informantes con sólo el alófono faríngeo fueron: C, T y Su; en el resto, también apareció el laríngeo. El alófono velofaríngeo lo encontramos en $\mathrm{P}$, $\mathrm{Tu}, \mathrm{S}, \mathrm{Du}$ y Ch. Todos ellos se sonorizan a veces, sobre todo, en posición intervocálica.

En el informante no universitario de Santiago, encontramos restos de la antigua aspiración [hosíko] hocico, [búho] búho, [hurakán] huracán. [hartapóbre] harta pobre (cierta clase de guineo).

$\mathrm{El}$ mismo fenómeno se produce también frecuentemente, según $\mathrm{M}$. Graell ${ }^{16}$, en las zonas rurales del país: [hasér] hacer, [hwír] huir, [húye] huye, [hayár] hallar, [hedjóndo] hediondo.

\subsection{Consonantes africadas.}

El fonema africado sordo, $/ \$ /$, presenta en el español de Panamá varias soluciones, tanto en cuanto al modo - africado o fricativo- como en cuanto al lugar de articulación. La descripción de los alófonos registrados es la siguiente:

3.4.1. Alófonos africados sordos: hemos encontrado tres tipos:

3.4.1.1. Africado alveoloprepalatal sordo, con dos variantes:

a) La formada por oclusión (duración media: 6 c. s.) ${ }^{17}$ más fricación (duración media : 6 c. s.); la frecuencia media de la fricación comienza a los $4.000 \mathrm{~Hz}$.

b) La formada por dos fricaciones, la segunda de mucha más intensidad; esta diferencia de intensidad es la que hace que se perciba como africada:

15 Op. cit., pág. 47.

16 . cit., pág. 62 .

17 Los valores, tanto de duración (c. s.) como de frecuencia (Hz.), que demos en lo sucesivo son siempre, si no indicamos lo contrario, valores medios. 
$1 .^{\mathrm{a}}$ fricación $\left(5,8 \mathrm{c}\right.$. s.) $+2 \mathrm{~g}^{\mathrm{a}}$ fricación $(5,8 \mathrm{c}$. s. $)$; comienzo de la fricación, a una frecuencia media de: $4.260 \mathrm{~Hz}$.

En la figura 4, aparece el sonograma de la africada prepalatal sorda, en trocha, de un informante de Jaqué. Este sonido consta de dos momentos fricativos: el primero, que correspondería a la oclusión, tiene menos intensidad que el segundo. Esta diferencia de intensidad entre los dos momentos es lo que hace que se perciba como una consonante africada.

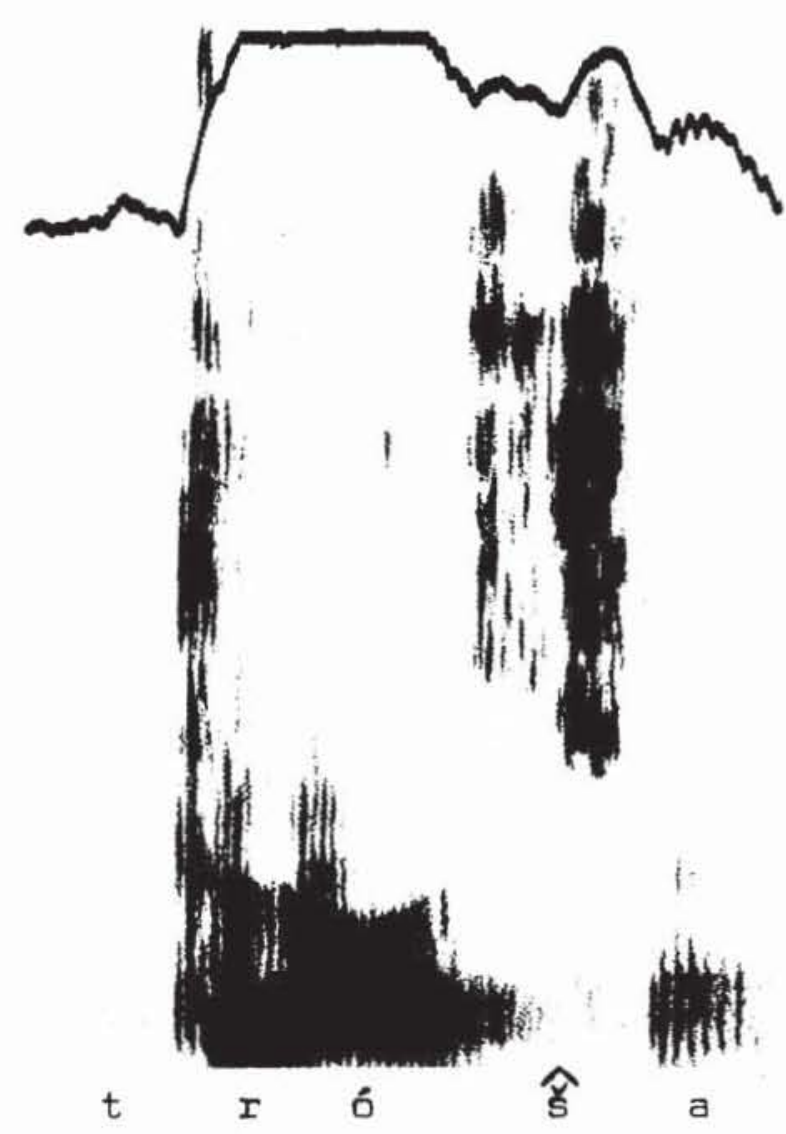

Fig. 4.- Sonograma de la africada prepalatal sorda en trocha.

3.4.1.2. Africado prepalatal sordo: oclusión $(7,44$ c. s.) + fricación $(8,72$ c. s.) ; comienzo de la fricación : $2.700 \mathrm{~Hz}$.

En la figura 5, representamos un sonograma de este alófono en la palabra machete. Puede percibirse en él, inmediatamente después de la [a], y antes 
de la oclusión, una pequeña fricación, que indica una articulación no muy tensa del momento oclusivo.

\subsubsection{Africado mediopalatal sordo, con tres variantes:}

a) Oclusión ( 7,8 c. s.) + fricación ( 8 c. s.) ; la fricación comienza a los $2.200 \mathrm{~Hz}$.

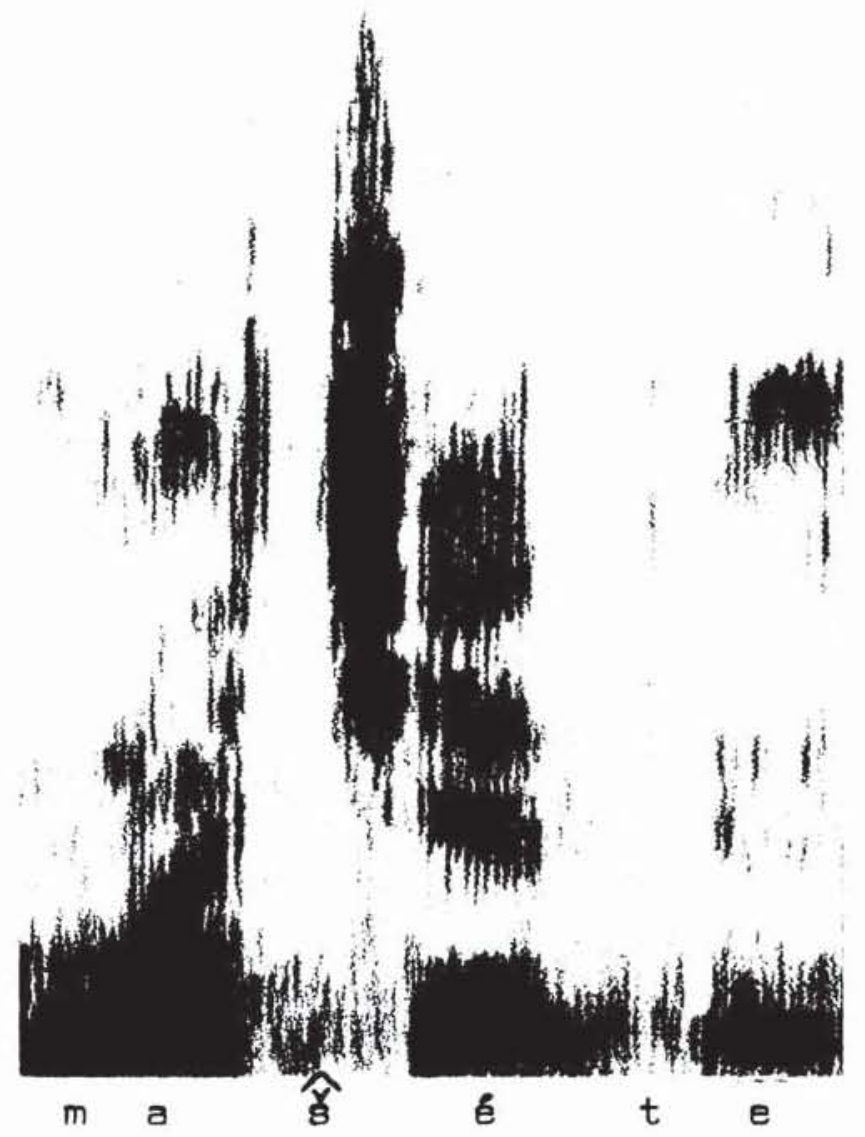

Fig. 5.-Sonograma de la africada prepalatal sorda en machete.

b) Fricación $(5,6$ c. s.) + fricación $(4,8$ c. s.) ; el comienzo de la fricación se sitúa en una media de $2.240 \mathrm{~Hz}$.

c) Fricación $(4,4$ c. s.) + fricación (2,8 c. s.) + fricación (11,6 c. s.) ; el comienzo medio de la fricación se produce a los $1.800 \mathrm{~Hz}$. 
En la figura 6, aparece el sonograma de la africada mediopalatal sorda en ocho, de un informante de Jaqué. Como puede verse, esta consonante consta de tres momentos: el primero y el último son fricativos muy intensos, con un grado de constricción normal; el segundo tiene una fuerte constricción próxima a la oclusión. Se percibe como africada.

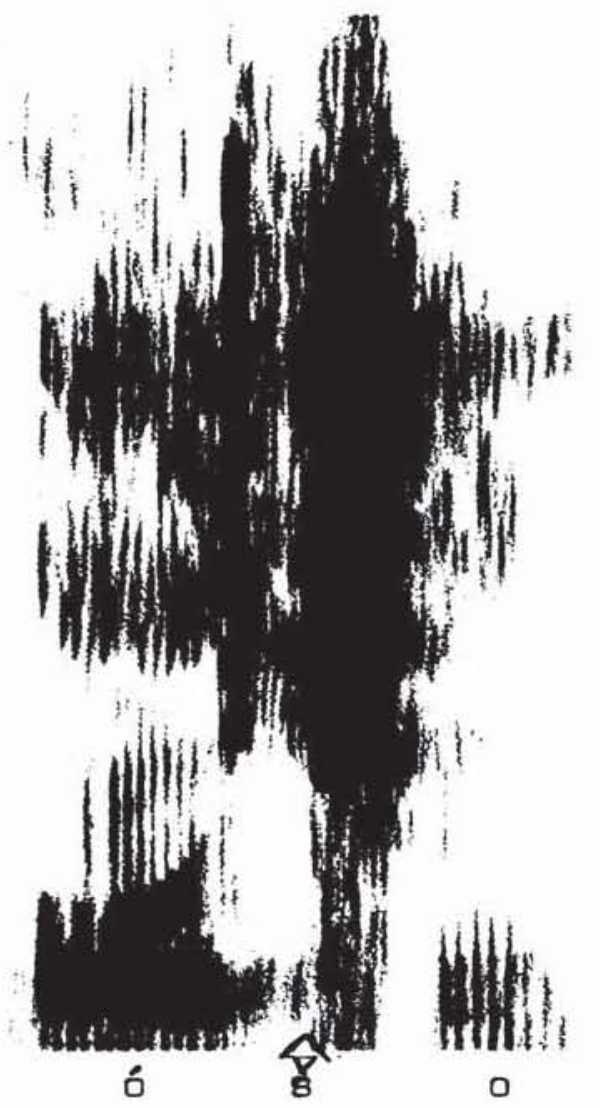

Fig. 6.-Sonograma de la africada mediopalatal sorda, en acho.

Como en el caso $b$ ) del $\S 3.4 .1 .1$, estos dos últimos tipos de africadas se perciben como tales a causa de la diferencia de intensidad que existe entre el momento fricativo final -de mayor intensidad-y el precedente.

A veces, el africado mediopalatal es algo arherente, aunque menos que el correspondiente canario. 
3.4.2. Alófonos fricativos ${ }^{18}$ sordos: hemos encontrado también tres tipos:

3.4.2.1. Fricativo alveoloprepalatal sordo; comienzo de la fricación: $3.800 \mathrm{~Hz}$.

3.4.2.2. Fricativo prepalatal sordo; comienzo de la fricación: $2.700 \mathrm{~Hz}$.

3.4.2.3. Fricativo mediopalatal sordo; comienzo de la fricación: $2.200 \mathrm{~Hz}$.

La figura 7 muestra los sonogramas de las fricativas mediopalatales sordas en [mušášo] muchacho.

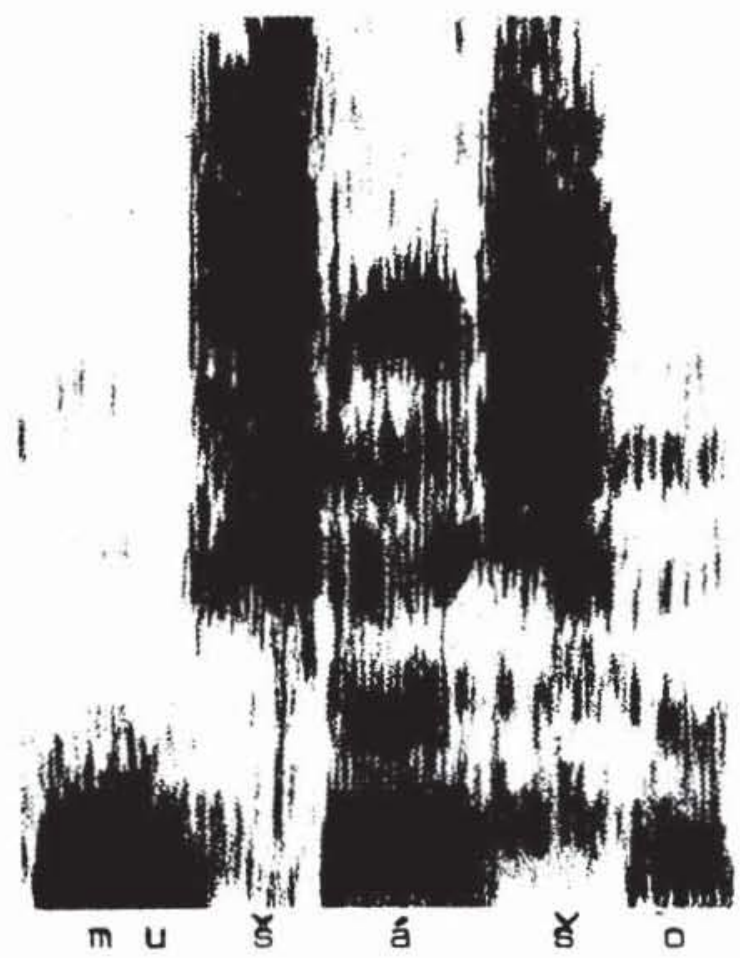

Fig. 7.-Sonograma de las fricativas mediopalatales, en muchacho.

En el siguiente cuadro, damos la distribución de los alófonos de / $/$ / por informantes y puntos de encuesta, con los porcentajes (en el cuadro, si indica que es la realización mayoritaria ; oc., que la realización es ocasional; 1 : realización alveoloprepalatal; 2 : realización prepalatal ; 3 : realización mediopalatal):

18 Robe, op. cit., pág. 54, no registra alófonos fricativos. 


\begin{tabular}{|c|c|c|c|c|c|c|}
\hline & {$\left[\begin{array}{ll}8 & 1\end{array}\right]$} & [ll 2] & {$\left[\begin{array}{ll}8 & 3\end{array}\right]$} & [ [ll 1 1] & [ [s 2$]$ & [ [ ll 3] \\
\hline $\mathrm{J} \ldots \ldots \ldots$ & & & 68 & & & 32 \\
\hline $\begin{array}{llll}\mathrm{J} u & \ldots & \ldots & \ldots\end{array}$ & & & 70 & & & 30 \\
\hline $\mathrm{C} \ldots \ldots \ldots \ldots$ & & 7,8 & & & 92,2 & \\
\hline $\mathrm{Cu} \ldots \ldots \ldots \ldots$ & & & 64 & & & 36 \\
\hline Pmu ... ... ... & & & 27 & & & 73 \\
\hline $\mathbf{P} \ldots \ldots \ldots \ldots$ & & & 31 & & & 69 \\
\hline $\begin{array}{lllll}\mathrm{Pu} & \ldots & \ldots & \ldots\end{array}$ & & & 24 & & & 76 \\
\hline $\mathrm{T} \ldots \ldots \ldots \ldots$ & & sí & & & oc. & \\
\hline $\mathbf{S} \ldots \ldots \ldots \ldots$ & & 79 & & & 21 & \\
\hline $\begin{array}{lllll}\mathrm{Su} & \ldots & \ldots & \ldots\end{array}$ & & 57 & & & & 43 \\
\hline $\mathrm{D} \ldots \ldots \ldots \ldots$ & & 15 & & & 85 & \\
\hline $\begin{array}{llll}\mathrm{Du} & \ldots & \ldots & \ldots\end{array}$ & & & 78 & & & 22 \\
\hline $\begin{array}{lllll}C h & \ldots & \ldots & \ldots\end{array}$ & 85 & & & 15 & & \\
\hline Chu $\ldots \ldots \ldots$ & & & sí & & & oc. \\
\hline
\end{tabular}

Como puede observarse, tanto los alófonos africados como los fricativos aparecen en todos los informantes en mayor o menor cuantía, en distribución libre, e independientemente de su grado de instrucción.

\subsection{Consonantes nasales.}

En el grupo de los fonemas nasales, hay que señalar:

3.5.1. Las soluciones que ofrecen las secuencias heterosilábicas de consonantes nasales, soluciones que son independientes del grado de instrucción de los informantes:

a) Secuencia $[\mathrm{mn}]$; por orden decreciente de frecuencia, da las siguientes soluciones: $1 .^{\mathrm{a}}:[\mathrm{n}]:$ [alúno] alumno; $.^{\mathrm{a}}:$ [gn] : [kolúgna] columna; $3 \mathrm{a}^{\mathrm{a}}:[\mathrm{mn}]$ y [gn]: [ímno] o [ígno] himno; $.^{\mathrm{a}}:$ [nn]: [ínno].

b) Secuencia $[\mathrm{nm}]$ : las soluciones, por orden decreciente de frecuencia, son las siguientes: $1 .^{\mathrm{a}}[\mathrm{m}]{ }^{19}$ : [komigo] conmigo; $2 .^{\mathrm{a}}$ : a mucha distancia de la anterior, [nm]: [ẽnmaskaráđo] enmascarado.

c) Secuencia [ns] : la solución mayoritaria en todos los informantes es [n]: [intrumếṇto] instrumento, [koṇtrutór] constructor, [tramparéṇte] transparente ${ }^{20}$. Los informantes cultos de Jaqué, Santiago, David, a veces, de Panamá, y los de Changuinola la realizan con relativa frecuencia como [ns] o como $[\mathrm{s}]$.

19 Esta es la única solución que registra Robe, op. cit., pág. 54.

20 Robe, op. cit., pág. 55, no registra esta solución. 
3.5.2. La nasal final ante pausa, tanto en sílaba tónica como en átona, puede realizarse como alveolar o como velar, con mayor o menor tensión, y puede nasalizar o no a su vocal núcleo silábico. Las soluciones, con sus porcentajes, son las siguientes: $1 .^{\mathrm{a}}:[-\mathrm{e} n]^{21}: 47 \% ; 2 .^{\mathrm{a}}:\left[\right.$ [en] $: 21,6 \% ; 3 .^{\mathrm{a}}$ : [-ẽn] : $20 \% ; 4 .^{\mathrm{a}}:\left[\right.$-ẽ] $: 9,6 \% ; 5 .^{\mathrm{a}}:[$-en $]: 1,8 \%{ }^{22}$.

3.5.3. Pese a la abundante aparición de la nasal velar ante pausa, no registramos ni un solo caso de [n] como índice de juntura interna abierta; siempre obtuvimos [ẽnóho] para enojo y en ojo, y [ẽnágwa] para enaguas y en aguas, respondiendo a las correspondientes preguntas del Cuestionario, y [konắmbre] con hambre, [ẽnómbros] en hombros, etc., que aparecieron en otros lugares del Cuestionario o en las narraciones espontáneas, que siempre grabamos.

\subsection{Fonemas vibrantes.}

3.6.1. El fonema vibrante simple, /r/, se realiza generalmente como [r], a veces, fricativo, sobre todo en posición postnuclear, posición de neutralización. $\mathrm{E}$ l fonema $/ \overrightarrow{\mathrm{r}} /$ se suele realizar como vibrante múltiple, $[\overline{\mathrm{r}}]$; a veces, aparece como $[\mathrm{r}]$ o como asibilado, [r] . No hemos encontrado la variante fricativa uvular sonora que señala Robe ${ }^{23}$.

En el cuadro siguiente ofrecemos las realizaciones del fonema $/ \vec{r} /$, con sus porcentajes correspondientes, tanto en posición inicial como medial.

\begin{tabular}{|c|c|c|c|c|c|c|c|}
\hline & {$[\vec{r}-]$} & {$[\mathrm{r}-]$} & [r̈-] & {$[-\bar{r}-]$} & {$[-\mathbf{r}-]$} & {$[-\dot{r}-]$} & {$[-I-]$} \\
\hline 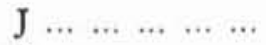 & 67 & 28 & 5 & 100 & & & \\
\hline Ju $\ldots \ldots \ldots \ldots$ & 4 & 6 & 90 & 4 & & 94 & 2 \\
\hline $\mathrm{C} \ldots \ldots \ldots \ldots$ & si & oc. & & sI & $\alpha$. & & \\
\hline $\mathrm{Cu} \ldots \ldots \ldots \ldots$ & 100 & & & 100 & & & \\
\hline $\begin{array}{llllll} & \text { Pmu } & \ldots & \ldots & \ldots & \ldots\end{array}$ & 100 & & & 100 & & & \\
\hline 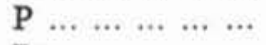 & si & $\propto$ c. & & 100 & & & \\
\hline $\mathrm{Pu} \ldots \ldots \ldots \ldots$ & si & oc. & & 100 & & & \\
\hline $\mathrm{T} \ldots \ldots \ldots \ldots$ & si & oc. & & 100 & & & \\
\hline 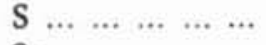 & 100 & & & 100 & & & \\
\hline Su $\ldots \ldots \ldots \ldots$ & 71 & 29 & & 100 & & & \\
\hline $\mathrm{D} \ldots \ldots \ldots \ldots$ & 100 & & & 100 & & & \\
\hline $\mathrm{Ch} \ldots \ldots \ldots \ldots$ & 43 & 32 & 25 & 100 & & & \\
\hline $\begin{array}{ccccc}C h u & \ldots & \ldots & \ldots & \ldots\end{array}$ & si & oc. & & 100 & & & \\
\hline
\end{tabular}

21 Donde [e] representa cualquier vocal, tónica o átona.

22 Robe señala también que pueden darse tanto las realizaciones velares como las alveolares: op. cit., pág. 55.

23 Op. cit., pág. 51 . 
3.6.2. La realización [ř $]$, asibilada alveolar, mencionada antes, presenta un primer formante a los $480 \mathrm{~Hz}$. y un segundo a los $1.000 \mathrm{~Hz}$. La fricación comienza inmediatamente por encima de los $1.000 \mathrm{~Hz}$; no supera los $8.000 \mathrm{~Hz}$. En la figura 8 puede verse un sonograma de esta realización, en la palabra reloj, pronunciada por un informante de Jaqué.

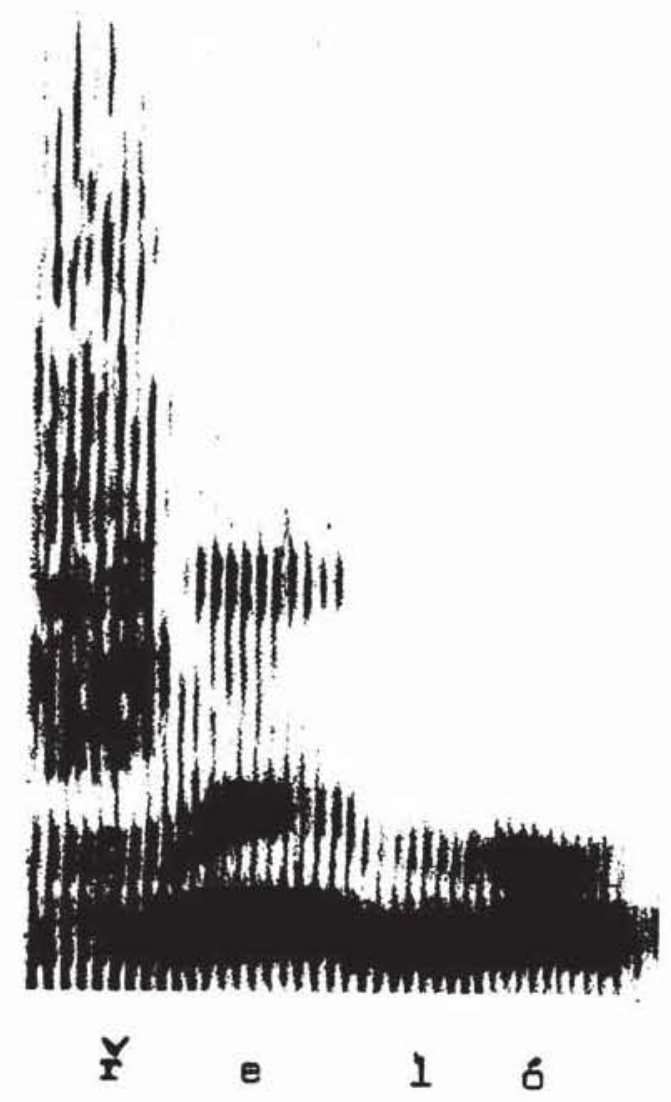

Fig. 8.-Sonograma de la líquida asibilada, [ř] en [řeló] reloj.

3.6.3. El alófono [-r] implosivo se realiza con relativa frecuencia, independientemente de la instrucción de nuestros informantes, como [-1]. Ocasionalmente, se ha perdido en los informantes no universitarios de Las Tablas y Colón, y en Jaqué. La informante no universitaria de Panamá lo pronunció, ocasionalmente, como [-n]. 
3.6.4. Secuencias heterosilábicas. Las secuencias $[\mathrm{rs}]$ y $[\mathrm{rl}]$ rara vez se reducen a [s] y a [1], respectivamente. [rn] se mantiene siempre ${ }^{24}$.

\subsection{Consonantes laterales.}

3.7.1. El fonema $/ 1 /$, en posición postnuclear, se realiza, a veces, como [-r] en David, y en los informantes no universitarios de Colón, Las Tablas y Santiago. Se perdia, ocasionalmente, en el informante de menor instrucción de Colón.

3.7.2. El fonema palatal lateral no existe en Panamá. El ycísmo es general.

\subsection{Acento.}

Los cambios acentuales no son muy frecuentes, pero se encuentran, de un modo $\mathrm{u}$ otro, en todos los informantes: en universitarios: máis, máestro, méndigo, ávaro; en los demás: máis, méndigo, ávaro, [almasígo] almácigo.

\subsection{Entonación.}

A continuación, vamos a examinar algunos rasgos de la entonación del español panameño. Los materiales analizados son grabaciones realizadas de conversaciones entre hablantes de la capital. La metodología que empleamos es la indicada por A. Quilis en otros trabajos anteriores ${ }^{25}$.

La entonación desempeña diversas funciones en la comunicación: unas son extrictamente lingüísticas, y se desarrollan en el nivel de la lengua; otras son expresivas, y otras sociolingüisticas; al hacer la descripción de las dos primeras funciones, indicaremos los rasgos que, a nuestro juicio, caracterizan la entonación panameña ${ }^{26}$ frente a la del español general.

24 Frecuentemente, carpintero se pronuncia como [kampintéro].

25 A. Quilis, Fonética acústica de la Lengua Española, Madrid, Gredos, 1." ed. 1." reimpresión, 1988; A. Quilis, «Entonación dialectal hispánica», Lingü̈stica Española Actual, VIII, 1985, págs. 145-190; A. Quilis, «La entonación gran canaria en el marco de la entonación española», Lingüística Española Actual, XI, 1989, págs. 55-88.

26 Sobre la entonación panameña, véase también Matilde Graell Stanziola, «Notas sobre la entonación en el habla panameña», Revista Lotería, marzo, 1974, págs. 17-25. 


\subsubsection{Funciones lingüisticas de la entonación.}

Las funciones de la entonación en el nivel lingüístico son: a) la función distintiva, que se realiza al oponer el enunciado declarativo al enunciado interrogativo; b) la función delimitadora o demarcativa, que puede ser distintiva o no.

3.9.1.1. El enunciado interrogativo tiene dos modalidades en español:

3.9.1.1.1. El emunciado interrogativo absoluto, que espera una respuesta sí o no. Se caracteriza por terminar con un fundamental ascendente. Las gráficas [1] a [3] responden a este tipo de enunciado; sus configuraciones coinciden con las del español general ${ }^{27}$.

[1] ¿Le gusta Panamá?

[2] ¿Usted habla alemán?

[3] ${ }_{i} Y t u$ ?

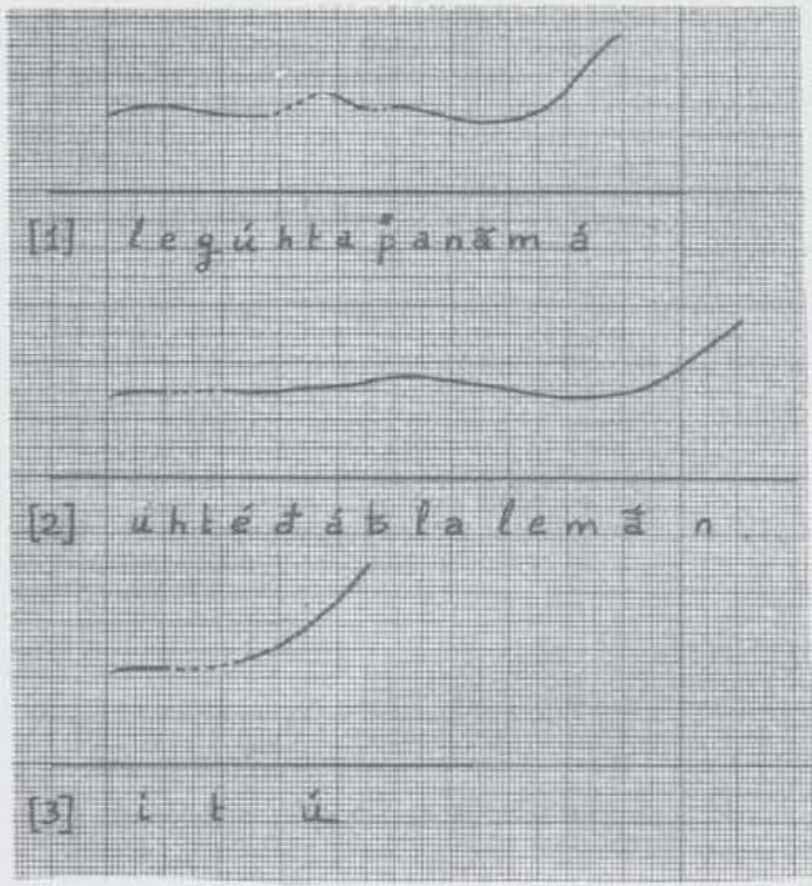

3.9.1.1.2. El enunciado interrogativo pronominal. Se caracteriza por la presencia de elementos gramaticales (no sólo pronombres, sino otras partículas interrogativas), que son por sí solos indicadores de la interrogación. 
c) $-i /-i e(s)$ : para la mayoría ${ }^{29}$.

d) $-\dot{u} /-\dot{u} e(s)$ : en los informantes universitarios de Colón y Santiago, $y$ en el no universitario de David; el resto forma el plural en $-\dot{u}(s)^{30}$.

\subsection{Género.}

\subsubsection{Género alternante.}

Encontramos siempre el masculino en las siguientes palabras: clima, vinagre, chinche 'insecto' y 'tachuela' ${ }^{31}$. Fueron siempre femeninas hinchazón, hacha, liendra. Las demás varian: el calor (en David, Santiago, informantes cultos de Panamá, Las Tablas y Jaqué); la calor, en el resto. El quemazón (informantes universitarios de Panamá, Jaqué y Colón); la quemazón, en el resto. La armazón (Las Tablas, Jaqué e informantes universitarios de Changuinola y Panamá); el armazón, en el resto. El pus (informante no universitario de Jaqué y en los universitarios de Panamá y Changuinola); la pus, en el resto. El sartén (David, Santiago, Changuinola, informantes universitarios de Colón y Panamá, y en los no universitarios de Jaqué y Las Tablas); la sartén, en el resto. Azúcar (m) en los informantes no universitarios de Jaqué y Santiago; azúcar (f), en el resto. Hambre (m) en los informantes cultos de Panamá y Colón y en el no culto de Changuinola. El costumbre en el informante no culto de David; la costumbre, en el resto.

\subsubsection{El género en la oposición $[-e],[-\varnothing] /[-a]$.}

Hemos encontrado las siguientes soluciones: tigre / tigresa: informantes cultos de Changuinola, Colón y Panamá; tigre / hembra del tigre en el in-

29 Excepciones: ajis, en el informante no culto de Changuinola; rubis, en los informantes cultos de Changuinola, Panamá, y en los no universitarios de Santiago y Colón. Albelís, en los informantes no cultos de Santiago y Changuinola, y en el universitario de Panamá; jabalís, en Changuinola, Las Tablas, en el informante no universitario de Santiago y en el universitario de Panamá.

30 Los plurales de Una virgen y de Una pared son, en la mayoría de los casos, Dos virgen y Dos pared.

Las palabras tijera, paragua, bigote, espalda, pantalón, tenaza aparecen generalmente en singular. Excepciones: tenazas en Colón y en los informantes cultos de Panamá, Las Tablas, Santiago y David; Tijeras en los informantes cultos de Santiago y Changuinola, y en el no culto de David; pantalones en el informante no culto de Santiago, y paraguas en el informante no culto de David.

s1 Excepción: la chinche, 'tachuela', en el informante no universitario de Changuinola. Tachuela apareció en los dos informantes de la mencionada localidad. 
formante culto de David: tigre / tigre hembra en el informante culto de Las Tablas; el tigre / la tigre en los informantes cultos de Santiago y Panamá; tigre / tigra en los informantes no cultos de David, Santiago, Changuinola, Colón y Jaqué. El juez / la juez, el jefe / la jefe (informantes cultos de $\mathrm{Pa}$ namá, Colón, Santiago, David y Las Tablas); juez / jueza, jefe / jefa, en el resto. Actor / actriz (Colón, e informantes cultos de Panamá y Las Tablas); actor / actora (informantes no universitarios de Jaqué y Changuinola, y en los universitarios de David y Panamá).

\subsubsection{Oposición $[-o] /[-a]$ en los sustantivos animados.}

La distinción de género en sustantivos usados tradicionalmente como masculinos tiene el siguiente comportamiento en el español de Panamá : venado / venada (Santiago, Panamá, Jaqué e informantes no cultos de Las Tablas, Colón y Changuinola); venado macho / venado hembra (informantes cultos de Las Tablas y David); el venado / la venado (informantes cultos de Changuinola y Colón). El abogado / la abogado (informantes cultos de Santiago, Las Tablas y Jaqué); abogado / abogada, en el resto. Testigo / testiga (en Jaqué, informantes no universitarios de Colón, Santiago y Las Tablas y en el culto de Changuinola); el testigo / la testigo, en el resto. Médico / médica (en el no universitario de Las Tablas); el médico / la médico (en los cultos de Santiago y Panamá); doctor / doctora (en David y en el universitario de Panamá); médico / doctora, en el resto. Loro / lora es general en el territorio ${ }^{32}$. Canal presenta las siguientes soluciones: a) para el riego: el canal en todo el territorio; $b$ ) para el desagüe de los tejados: la canal (Changuinola, Pananá e informantes cultos de Santiago y Colón); el canal (informante culto de Colón); caño (David e informante no universitario de Santiago); cañizo y caniso en Las Tablas ${ }^{33}$; la canaleta (informante universitario de Panamá).

\subsubsection{El género con función léxicosemántica.}

$\mathrm{El}$ género, con función léxicosemántica, tiene el siguiente tratamiento en nuestro territorio: jarro, $-a$ designan indiferentemente el mismo 'recipiente

32 La culebra / el culebra, en Jaqué; culebra / culebro, en los informantes no cultos de Jaqué y Las Tunas; sólo culebra en el resto.

s3 Aquí, la canal es la 'hendidura'. 
En el español general, este enunciado termina con un fundamental descendente; es decir, un patrón entonativo semejante al del enunciado declarativo; la diferencia entre éste y el interrogativo pronominal viene dada por la presencia de un elemento gramatical con función interrogativa, según ya hemos indicado. Como la economía de la lengua tiende a evitar redundancias, basta un solo signo para indicar la interrogación.

La configuración entonativa más abundante para este tipo de enunciado en el español de Panamá es la que termina con fundamental ascendente. Son enunciados como

[4] ${ }_{\text {¿ } Y}$ qué pelicula viste?

[5] ¿Cuánto cuesta una botella de ron?

[6] ¿Dónde vive usted?

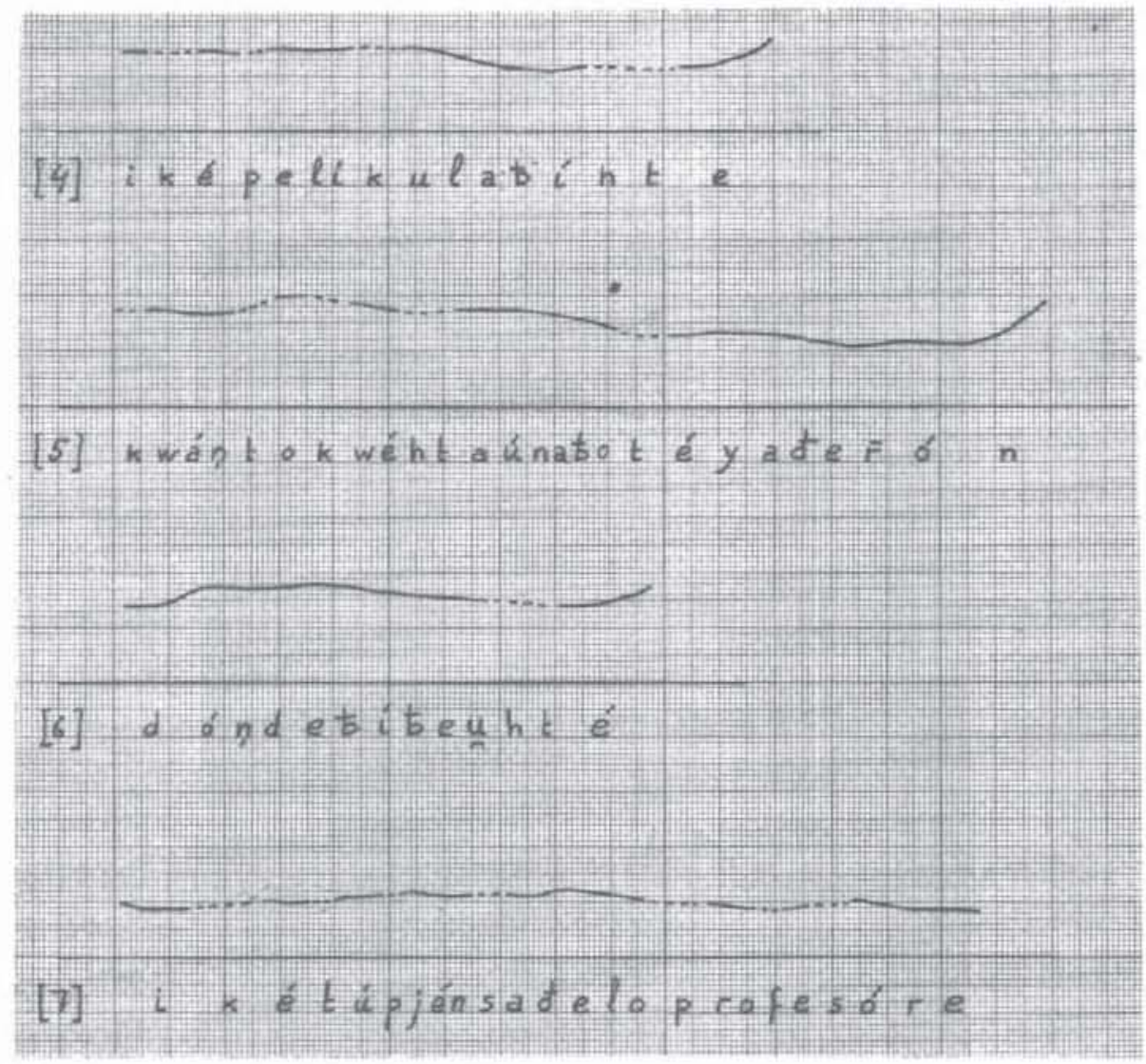

que serian considerados en el español general dentro de la función expresiva. El enunciado

[7] ¿ $Y$ qué tú piensas de los profesores? 
3.9.1.2. El enunciado declarativo se caracteriza por el final descendente del fundamental. Las gráficas [8] a [10] representan este tipo de enunciados.

[8] Me iria a viajar

[9] Se hablaba el español

[10] Eso no puede ser.

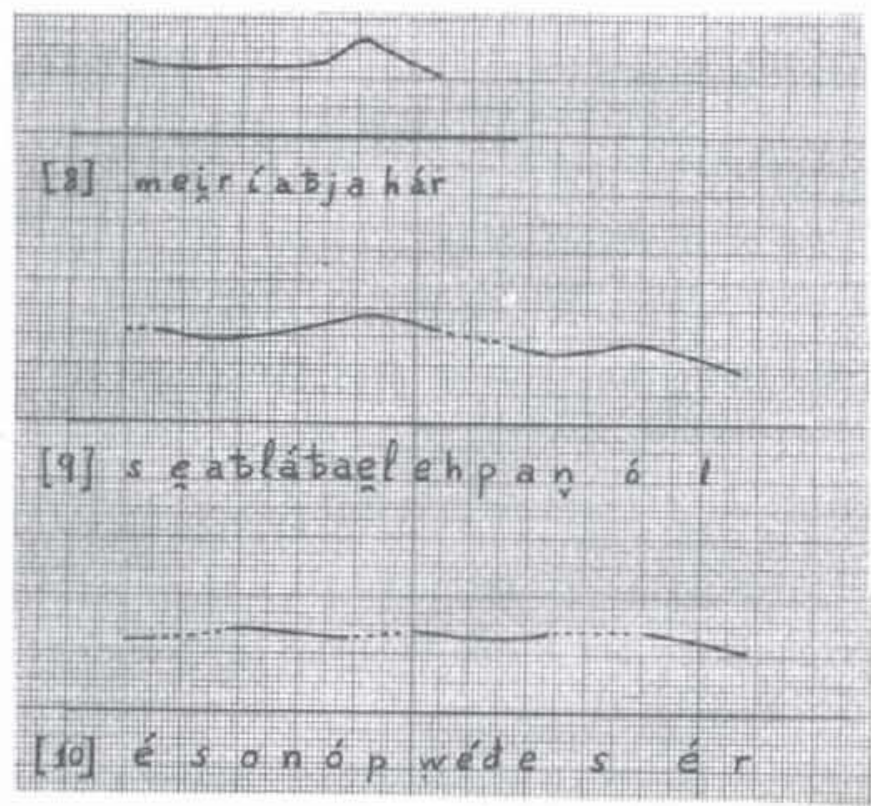

El fundamental es descendente, pero con un movimiento circunflejo que abarca principalmente la sílaba acentuada final del enunciado; en el español general, es descendente, pero sin este último movimiento de ascenso-descenso.

3.9.1.3. La función demarcativa, como dijimos, puede ser distintiva o no. Del primer caso, serian enunciados como

[11] Los alumnos, que viven lejos, llegan tarde

[12] Los alumnos que viven lejos llegan tarde

[13] Algunos, inquietos, preguntaban por ćl

[14] Algunos inquietos preguntaban por él

[15] Juan pregunta quién z'a a entrar

[16] Juan pregunta: ¿quién va a entrar?

[17] Juan: pregunta quién va a entrar.

En los casos [11], [13], [16] y [17], una inflexión del fundamental, seorida $n$ no ie na1sa. en alumnos. alcunos. breaunta v Juan resnectivamente. 
de cristal o de barro' en David, los informantes no universitarios de Santiago y Changuinola y en el universitario de Jaqué y de Panamá. El jarro es 'más pequeño y sin pico' en Panamá, informantes no universitarios de Jaqué y Colón, y en el informante culto de Santiago. Por el contrario, el jarro es 'más grande' en los informantes cultos de Las Tablas y Changuinola; el jarro es 'de metal' para el informante no universitario de Las Tablas; sólo existe jarra para el informante universitario de Jaqué.

Canasto, - $a$ designan al mismo recipiente, según los informantes cultos de Panamá, David y Santiago; para el no universitario de David, el canasto es 'para la ropa sucia', y la canasta, la 'del baloncesto'; la canasta es 'más abierta', para el informante culto de Las Tablas; es 'más grande' para el de Panamá ; es 'más pequeña' para el no universitario de Jaqué, y para el otro informante de la misma localidad, sólo existe canasta.

Banco, - $a$ son utilizados indistintamente por la informante universitaria de Panamá para designar a un 'asiento para varias personas'; banca 'asiento para varias personas, con respaldar' en Panamá, David, Santiago, Changuinola y Las Tablas; banco 'asiento para varias personas, sin respaldar', en David, Santiago, Changuinola, e informante culto de Jaqué; banco 'asiento de cuatro patas, sin respaldar' en Panamá e informante culto de Las Tablas.

Pozo 'pozo' y poza 'poza' en los informantes cultos de Panamá y en el no universitario de Jaqué. Sólo pozo 'id' en los informantes no universitarios de Panamá y Las Tablas y en los universitarios de Jaqué y Changuinola; pozo, $-a$ 'pozo' en los no universitarios de Santiago y Changuinola; pozo 'id' y poza 'ciénaga' en los informantes cultos de Santiago y Las Tablas y en los no universitarios de David y Colón; pozo 'id' y poza 'laguna de agua corriente', para el informante culto de David.

Bolso 'id' / - a 'recipiente de materia flexible, para llevar cosas', en David, Las Tunas, Panamá, informante culto de Santiago y en los no universitarios de Colón y Changuinola; bolso, - a 'bolso' en los informantes cultos de Panamá, Jaqué y Changuinola, y en el no universitario de Santiago; la bolsa es 'más pequeña', para el informante universitario de Jaqué.

Huerto, - $a$ 'terreno de pequeña extensión, junto a la casa, en el que se cultivan verduras, legumbres o árboles frutales', en David, Panamá, Changuinola y en los informantes no cultos de Santiago y David; huerto 'terreno de pequeña extensión, etc.', en Las Tablas e informantes cultus de Santiago y Jaqué; huerto 'cercado para guardar animales domésticos' y huerta 'terreno de cultivo', en el informante culto de Colón; huerta 'pastizal para caballos', en el informante culto de Santiago; huerta 'plantación de plátanos' en Las Tablas; huerta 'terreno, alrededor de la casa, sembrado de plantas ornamentales', en el informante culto de Jaqué; la huerta es 'más grande' para el informante no universitario de Jaqué. 
Barranco, - $\boldsymbol{a}$ 'barranco', en Las Tablas, informante universitario de Panamá e informantes no universitarios de David, Santiago y Changuinola; sólo existe barranco, 'id', para los informantes cultos de Jaqué, Panamá, Santiago, David y Changuinola; la barranca es 'más pequeña' en Colón y para el informante no universitario de Jaqué.

Charco 'poza del río' / - $a$ 'charco', en Changuinola, para los informantes cultos de Santiago y Las Tablas y para los no universitarios de David y Jaqué; charco 'id' / - $a$ 'poza del río', en Panamá, informantes no universitarios de Las Tablas y Santiago y en el universitario de David. Charco, - $a$ 'charco' para el informante culto de Jaqué ; charco 'id' / - $a$ 'depósito de agua detenida en un terreno', en Colón.

Hoyo 'id', general; hoya, a causa del yeísmo, es 'olla' o 'paila' en todos los informantes, con la excepción del no universitario de Jaqué; para él, es 'poza del río'.

\subsection{Pronombre.}

4.2.1. Uso del posesivo, en lugar del pronombre personal, con los adverbios de lugar.

En nuestras encuestas, apareció delante mío en el informante culto de Colón, y detrás tuyo en el informante universitario de Panamá, y en los no universitarios de David y Jaqué. El resto siempre delante de mí y detrás de ti.

\subsubsection{Adición de /-n/ y /-s/ en los pronombres enclíticos.}

La pérdida del sentimiento del plural, cuando los pronombres enclíticos se unen a un verbo usado como imperativo, lleva al hablante a añadir / $\mathrm{n} /$, que funciona siempre como morfema de número de la tercera persona del plural de la conjugación.

Formas en plural de los pronombres complementarios, como díganmen, váyansen, cállensen aparecen en Jaqué y en el informante culto de Las Tablas.

Del mismo modo, la pluralización de lo (tráenolos) aparece en Jaqué, en Santiago y en los informantes no cultos de Las Tablas y Changuinola. En los demás informantes, el uso es correcto. Kany ${ }^{34}$ no registra el fenómeno para Panamá.

34 American-Spanish Syntax, Chicago, London, 1963, págs. 112-114. 
De esta función, propia del español general, participa también el dialecto panameño.

Otras muchas veces, la función demarcativa no es distintiva, aunque resulta imprescindible para la interpretación del mensaje y también adopta diferentes comportamientos en diferentes tipos de enunciados. Veamos algunas de estas funciones.

\subsection{El estilo directo frente al estilo indirecto.}

Del primero, son los enunciados

[18] Mi mamá me dice: "¿Qué vas a hacer?"

[19] Mi mamá me dice: "Bueno, si estás tan insegura ..."

en ambos, el descenso del fundamental después de dice, sin pausa, es suficiente para delimitar las dos partes del enunciado. El enunciado

[20] Mi mamá me preguntaba pues qué yo que queria estudiar

es un caso de estilo indirecto. Aquí, el movimiento del fundamental es ascendente en preguntaba y por sí solo (tampoco hay pausa) delimita el enunciado,

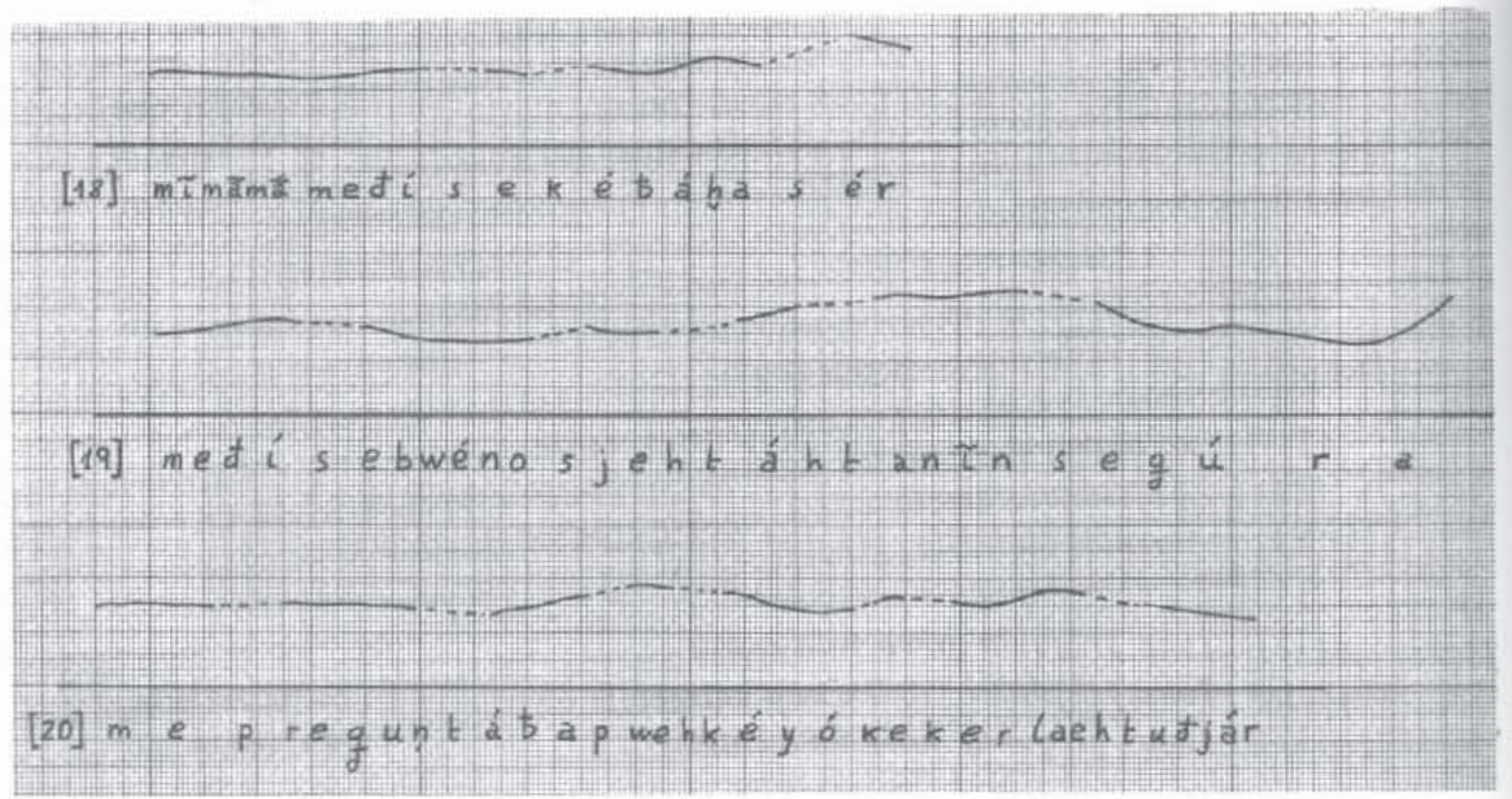

En estos casos, el comportamiento del fundamental es idéntico al del es- 
4.2.3. Concurrencia de "me", "te" con "se".

Las respuestas siempre coincidieron con el uso normativo: Se me olvidó.

\subsection{3. "Nosotros" usado como femenino.}

En todo el país, se usa el plural masculino nosotros como femenino, en sustitución de nosotras: "Mañana nosotros iremos vestidas de blanco." Kany ${ }^{35}$ no registra el fenómeno para Panamá. R. Lenz pensaba que este fenómeno sería común en todas partes; para él, "La existencia de dos géneros distintos en la primera persona es una anomalía que no recuerdo haber encontrado en ningún otro idioma. Las lenguas indoeuropeas no distinguían nunca primitivamente las dos primeras personas según el género. Las personas están presentes, ¿qué necesidad tienen de decir: yo, hombre, y tú, mujer; a no ser que quiera hacer hincapié en la diferencia de sexo?" ${ }^{36}$.

\subsubsection{Sustitución del posesivo por un pronombre personal.}

Como el pronombre su resulta ambiguo, el hablante lo sustituye por " $d e$ + pronombre personal" o añade este sintagma al enunciado con $s u$ ("La casa de él"; "Su casa de usted"). En nuestras encuestas, ésta ha sido la solución generalizada: "Está en la casa de él, de usted, etc.", por "Está en su casa", que sólo apareció en Santiago; y lo mismo "Este lápiz es de él, de usted, etc.", respuesta general, en lugar de "Este lápiz es suyo", que sólo apareció en los informantes cultos de Panamá y en el no universitario de Santiago.

Lo mismo ocurre con la construcción de nosotros en lugar de nuestro, aunque las respuestas no han sido tan generales como en el caso anterior: "La casa de nosotros", por "Nuestra casa", apareció en todos los informantes; ambas formas se dieron en los informantes cultos de Panamá, Las Tablas, Santiago, David, Changuinola y en el informante no universitario de Colón. En este caso, la analogía con "de + pronombre personal" señalado antes, y la pérdida del vuestro en favor de la forma analítica de ustedes fa-

ss Op. cit., págs. 99-100.

36 La oración y sus partes, Santiago de Chile, 1944, págs. 248-249. 
3.9.1.3.2. En la enumeración, es también importante su papel. En el español de Panamá, todos los grupos que configuran la entonación terminan con movimiento ascendente del fundamental, esté presente o no el nexo $y$ antes del último. Éste siempre termina con fundamental descendente.

[21] No me decidía si por medicina, si por leyes, si por cómputo

[22] Habian venezolanos, brasileiros, portugueses y eso.
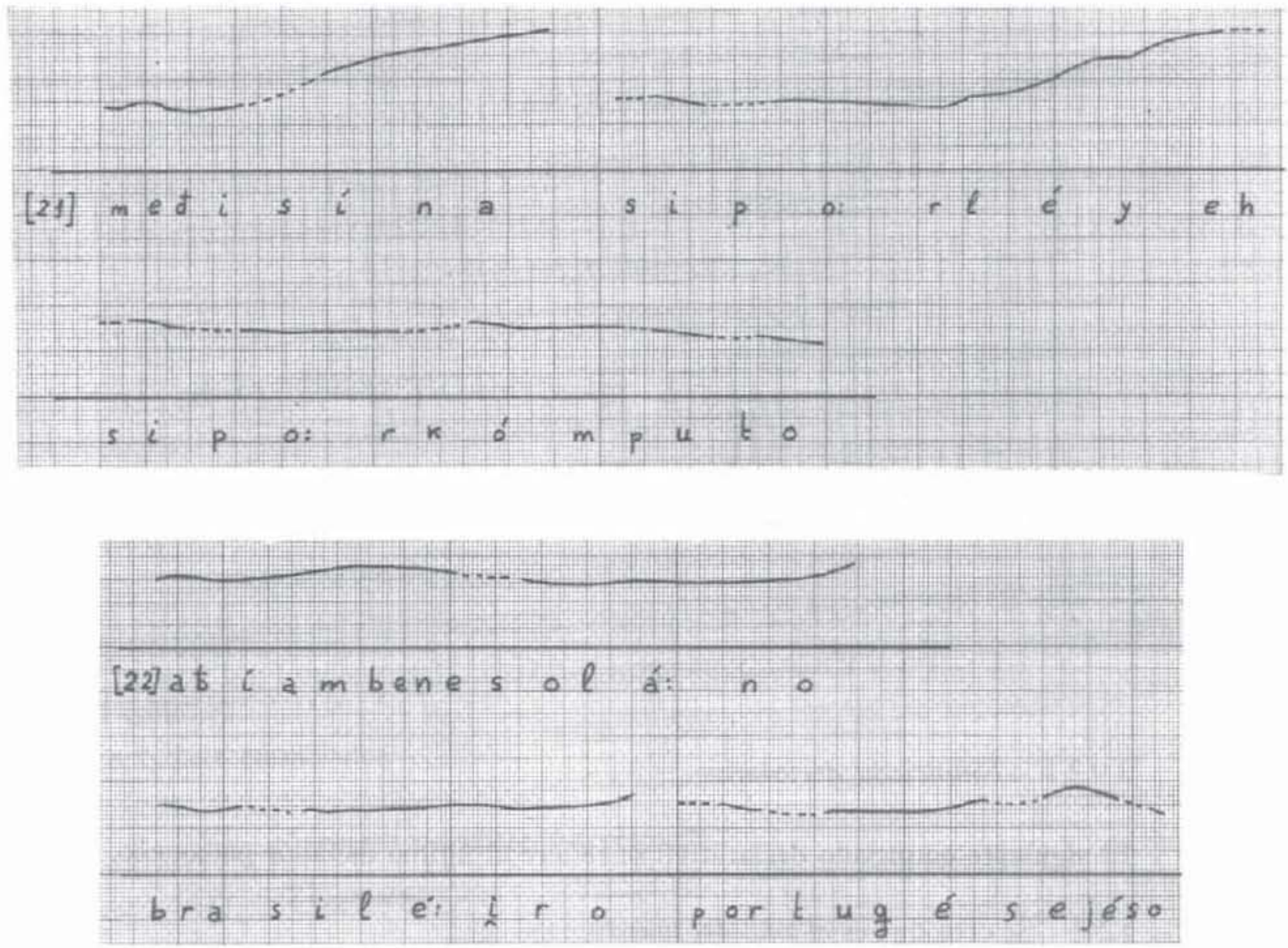

3.9.1.3.3. Lo mismo funciona, como en el español general, en el caso de los complementos hiperbatizados, o en el de la delimitación del sujeto del sintagma verbal. En el enunciado

[23] pero, cuando uno trabaja con personas, el comportamiento varía puede observarse el siguiente movimiento del fundamental: horizontal en pero; ascendente en uno, trabaja, persona (son enunciados incompletos); 
vorecieron la aparición de "La casa de nosotros". Kany no menciona estas formas para Panamá ${ }^{37}$.

\subsubsection{Posición del pronombre sujeto en las preguntas.}

En las Antillas y en Venezuela, el pronombre sujeto (con excepción de él, ella y sus plurales) se sitúa frecuentemente antes del verbo: ¿Qué tú quieres? es la construcción habitual, en lugar de la más general ¿Qué quieres tú? Kany ${ }^{38}$, que atribuye el fenómeno, y creemos que con razón, a una mera confusión entre ${ }_{b} T u ́$ quieres? y $\dot{Q} Q u e ́$ quieres?, en lugar de buscar una influencia negra o una contaminación del inglés, no lo señala para Panamá. En nuestras encuestas, el fenómeno ha aparecido en Jaqué y Colón, en Panamá, en el informante culto y en la no universitaria; en Santiago y David, en los informantes cultos y, en Changuinola, en el no universitario.

Nuestras observaciones sobre el terreno, al margen de las encuestas, han puesto de relieve que el mencionado patrón interrogativo ¿̇Qué tú quieres? está en expansión por todo el país. Los focos fueron Colón y Panamá, donde el fenómeno comenzó hace aproximadamente treinta años, con la llegada de importantes contingentes de exiliados cubanos; hoy, las generaciones jóvenes emplean constantemente esta estructura interrogativa, principalmente en los núcleos urbanos.

\subsubsection{Colocación del pronombre con formas impersonales de la conju- gación.}

Nuestras encuestas muestran preferencia por la colocación del pronombre después del verbo, cuando la frase es afirmativa: Al venir yo, En llegando yo ${ }^{39}$, Después de ido tú, pero antes del verbo cuando es negativa: Sin tú decir nada. No obstante, el orden inverso presenta las siguientes peculiaridades: Al yo venir: en Panamá, Colón e informante culto de Jaqué. Sin decir nada $t u$ : informante culto de Colón y en los no universitarios de Santiago y Las Tablas. En yo llegando: informantes cultos de Santiago y Changuinola. Después de tú ido: informantes cultos de Santiago, Panamá y Jaqué, y en la no universitaria de Changuinola.

37 Op. cit., págs. 47-48.

38 Op. cit., pág. 125.

39 Llegando yo: en el universitario de Panamá. 
sintagma verbal. Pensamos que este final descendente en comportamiento es expresivo; en el español general, es ascendente.

\subsubsection{Funciones de la entonación en el nivel expresivo.}

La entonación es el vehículo idóneo para transmitir la expresividad de un enunciado. Aquí vamos a dar sólo unos ejemplos de nuestro dialecto:

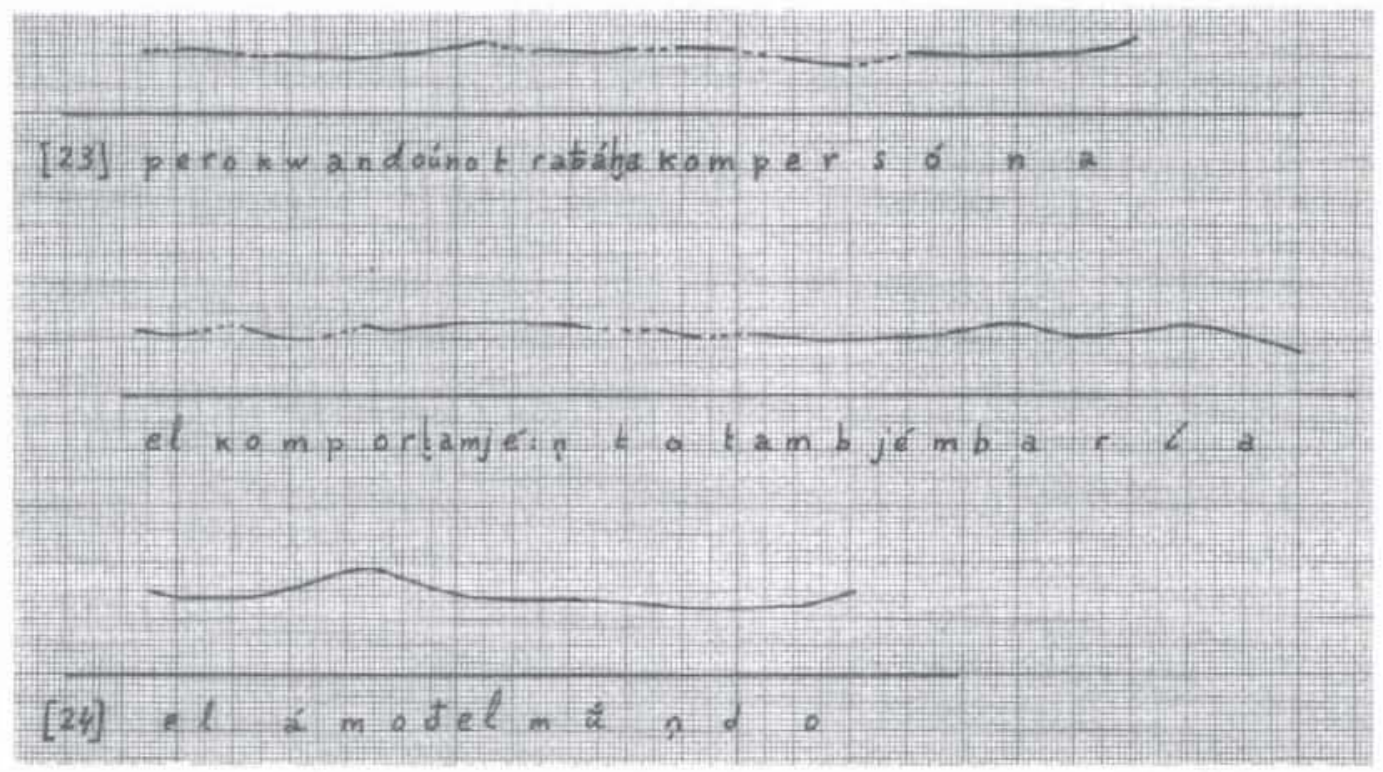

\subsubsection{Enunciado declarativo.}

El siguiente enunciado declarativo se refiere al último dictador panameño.

[24] Se cree que es el amo del mundo.

Obsérvese: a) el tempo lento; b) el movimiento circunflejo del fundamental en la palabra amo, cuyo significado es clave en el enunciado; c) la ligera elevación del fundamental en la [-o] de mundo.

El enunciado

[25] El trabajo anterior, realmente, era de secretariado

refleja la decepción del hablante por el tipo de trabajo que debía desarrollar: 


\subsubsection{Enunciado interrogativo.}

Los enunciados

[26] ¿Te acuerdas?

[27] ¿Tú fumas?

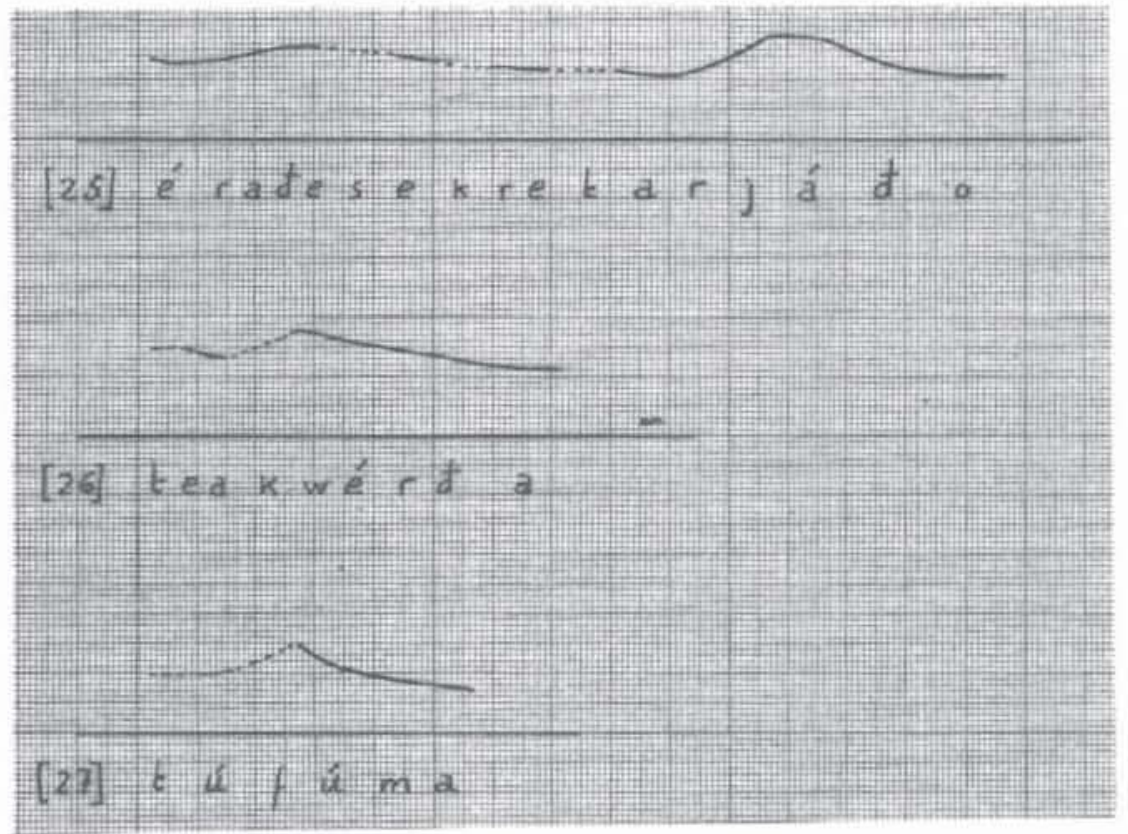

tienen un fundamental fuertemente descendente; el movimiento de todo el contorno melódico es realmente circunflejo.

Los enunciados

[28] ¿Siempre decidiste psicologia?

[29] ¿Te gusta?

son preguntas con un fundamental descendente precedido de un movimiento circunflejo más o menos amplio.

Los enunciados

[30] ${ }_{6}$ Del doctor?

[31] ¿La viste?

son preguntas con matiz de sorpresa. El movimiento circunflejo del funda(c) Consejo Superior de Investigaciones Científicas http://revistadefilologiaespañola.revistas.csic.es Licencia Creative Commons 3.0 España (by-nc) 


\subsubsection{Pronombres "lo", "la", "le".}

Los pronombres lo y $l a$ y sus plurales se emplean, de acuerdo con su origen etimológico, como objeto directo en todo el territorio. Del mismo modo, le y les se usan siempre como objeto indirecto.

$\mathrm{El}$ uso de $l e$ como complemento directo referido al femenino, en vez de $l a$ (" $L e$ vi" por " $L a$ vi"), señalado por Kany ${ }^{40}$ para el Ecuador y el Paraguay, solamente, apareció en el informante no culto de Jaqué.

\subsubsection{Uso de "le" por "les".}

El empleo de le por les en frases como "A mis hermanos le dije que vinieran”, no señalado por Kany ${ }^{41}$ para Panamá, apareció en los informantes cultos de Las Tablas, David y en el universitario de Panamá.

\subsubsection{Empleo de "se los (las)" por "se lo (la)".}

Como es sabido, el deseo de indicar el número en el ambiguo se lleva en muchas regiones de América y de España a la adición del morfema de plural $\{-\mathrm{s}\}$ al objeto directo $l o$, aunque la cosa referida esté en singular. Los resultados en nuestras encuestas muestran que el uso correcto es el general : contravinieron la norma los informantes cultos de Las Tablas y Changuinola, y los no universitarios de Jaqué y Santiago ${ }^{42}$.

Kany ${ }^{43}$ señala el fenómeno en Panamá, tomando los datos de la obra de Lisandro Espino ${ }^{4}$.

\subsubsection{Vitalidad de "si".}

En amplias zonas del español, la forma reflexiva preposicional si (consigo, para sí, en sí, etc.) está siendo sustituida por él, ella, ellos, ellas. La ra-

\footnotetext{
40 Op. cit., pág. 103.

41 Op. cit., págs. 107-109.

4 En el Cuestionario, las preguntas son las siguientes:

- *Compré un toro a los ganaderos $=$ se lo / los compré.»

- «Compré un toro a las patronas $=$ se lo / los / las compré. $\nsim$

- «Compré una vaca a las patronas $=$ se la / las compré.»

- «Compré una vaca a los ganaderos $=$ se la / las compré.»

43 Op. cit., pág. 111. Cita los siguientes ejemplos tomados de Espino: «La advertencia se las hizo a todos ... El dinero ... se los trajo a su cuñado* (pág. 139).

4 Lisandro Espino, Ensayo de critica gramatical. Panamá, 1925.
} 

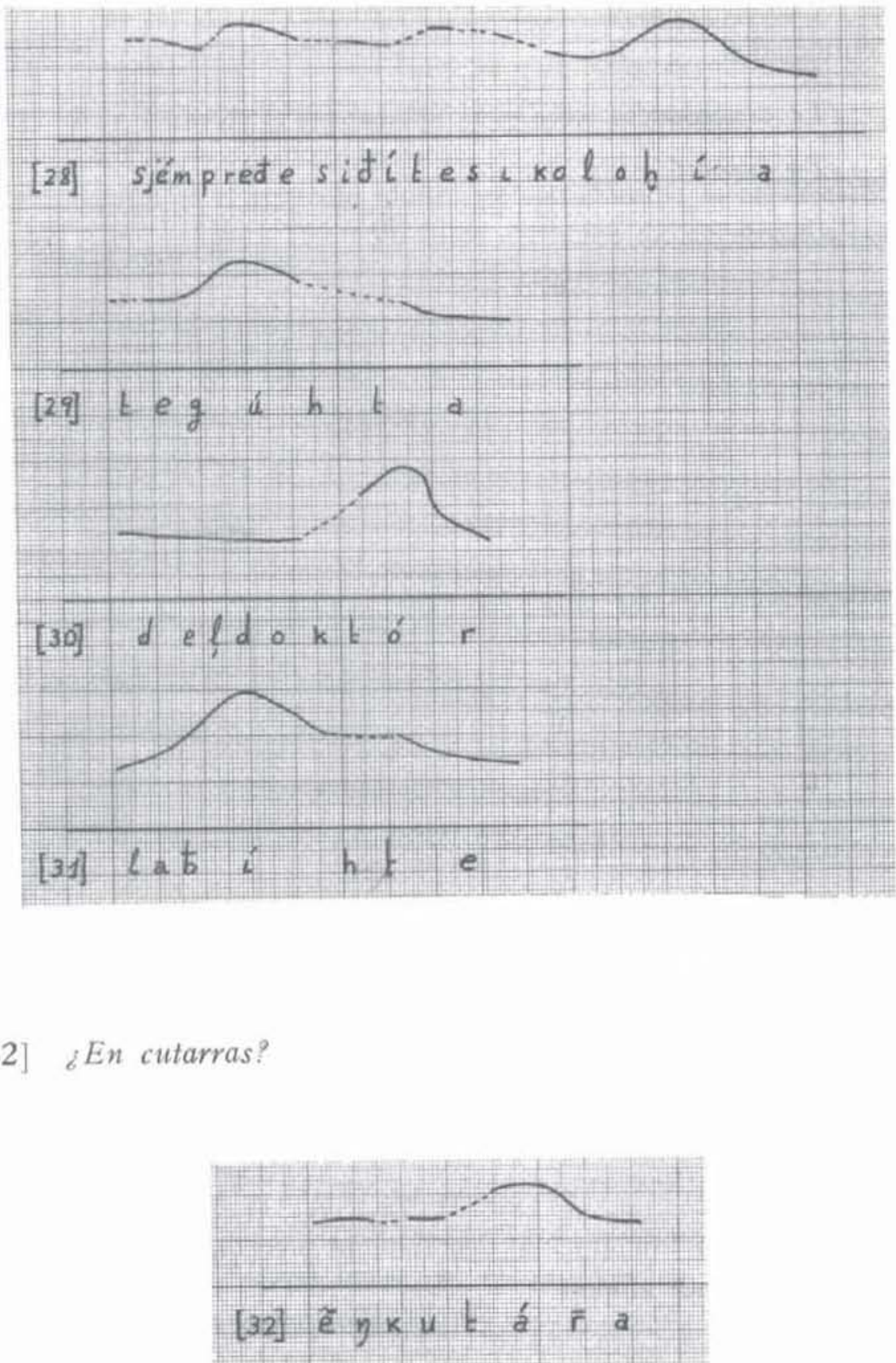

es una pregunta exclamativa: el locutor se asombra de que un profesor vaya a clase en cutarras. Su configuración entonativa es semejante a la del enun. . 
zón de este cambio, como apunta Kany ${ }^{45}$, es la de facilitar la comprensión: $s i$, que es una forma invariable en género y número, tiene varios significados, y la comunicación, a veces, no es todo lo univoca que desea el hablante; por ello, el deseo de especificar el número, el género e incluso la persona induce a relegar el empleo del si y a utilizar otros pronombres.

En nuestras encuestas ${ }^{46}$, el resultado ha sido el siguiente:

- Lo quiere(n) para sí, en Santiago, en los informantes cultos de $\mathrm{Pa}$ namá y Las Tablas, y en los no universitarios de Jaqué y David; Lo quieren para él, en el resto.

- Exige de él mismo: en Colón, en el informante culto de Changuinola y en los no universitarios de Santiago y Las Tablas. En el resto, Exige de si mismo.

- Se lo llevó con él: en Colón, en los informantes cultos de Jaqué, Panamá, Changuinola y en los no universitarios de David, Santiago y Las Tablas. Se lo llevó consigo, en los demás informantes.

Otro aspecto de este mismo problema es el empleo del si en expresiones como Volver en si ${ }^{47}$, si bien, en este caso, si se usa, erróneamente, para todas las personas ${ }^{48}$. Los resultados de nuestras encuestas son los siguientes:

- Volvi en mí en los informantes cultos de Panamá, Colón y Las Tablas. En el resto, Volvi en sí.

- Vuelve en ti: en los informantes cultos de Panamá, Las Tablas y Changuinola. En los demás informantes, Vuelve en sí.

Predomina, como puede verse fácilmente, el uso incorrecto de sí.

4s Op. cit., pág. 120.

46 En el Cuestionario, las preguntas sobre este punto son: «Lo quiere(n) para sf / para él, ella, ellos, etc.»; «Exigir de sí mismo / de él mismo, etc.»; «Se lo llevó consigo / con el, ella, etc.w.

47 En el Cuestionario, hay dos entradas para este mismo problema: «Volvl en mi / si» y *Vuelve en $t i$ / sim.

48 Cuervo, en sus Apuntaciones criticas sobre el lenguaje bogotano (tomo II de sus Obras, segunda edición, Bogotá, Instituto Caro y Cuervo, 1987, pág. 358), decla: "Con frecuencia oimos decir: «yo no volví en sí sino después de cuatro horas»; «cuando volviste en sí. Es de toda evidencia que, siendo sí pronombre de tercera persona, no puede representar a la primera (yo) ni a la segunda (tú o vos), y que consiguientemente habremos de corregir esos adefesios diciendo: "yo volví en mi»; «cuando volviste en ti»." 


\subsection{Adjetivo.}

\subsubsection{Uso de "cuál" por "qué".}

El empleo del adjetivo interrogativo ¿cuál? por ¿qué?, frecuente en el español antiguo, es de uso casi general en Panamá. Se prefiere ${ }_{b} C u a ́ l$ casa te gusta más? a sQué casa?; esta última forma sólo apareció en Jaqué y en los informantes no universitarios de Colón y Changuinola.

\subsection{Verbo.}

\subsubsection{Cambio de acentuación.}

Por analogía con las demás personas del paradigma de su tiempo, puede producirse el mantenimiento de la diptongación y del acento sobre la vocal tónica. En nuestras encuestas, hemos encontrado: téngamos "tengamos" en los informantes no universitarios de Panamá y Jaqué; quiéramos "queramos", en el informante universitario de Panamá, en el de Colón y en los no universitarios de Panamá y Jaqué; váyamos "vayamos", en los no universitarios de Panamá, Colón y Jaqué; también vénganos "vengamos", en los informantes no universitarios de Santiago y Jaqué ${ }^{49}$.

\subsubsection{Formas diptongadas y no diptongadas.}

En unos casos, la vocal temática aparece sin diptongar, por analogía con el infinitivo: cozo "cuezo", en Las Tablas e informantes cultos de Jaqué, Colón y Changuinola ; forzo "fuerzo", en Las Tablas, Panamá, Jaqué, Colón, David y Santiago; renego "reniego" y trona "truena", en el informante culto de Colón; tosta "tuesta", en los informantes cultos de Jaqué y Las Tablas, y en el no universitario de Santiago; apreta "aprieta", en el informante culto de Jaqué. Al margen de las encuestas, hay que señalar que formas como colo "cuelo", solde "suelde" son comunes en los estudiantes universitarios.

En otros casos, se produce el fenómeno inverso: aparece la forma diptongada del infinitivo por analogía con otras personas del paradigma verbal y también, a veces, por analogía con el sustantivo correspondiente: empiedrar,

40 En el resto de los informantes, podamos, tengamos, queramos, vayamos, vengamos. 


\subsubsection{El enunciado}

[33] ${ }_{6}$ Cómo voy a tener yo la experiencia, si no me han dado la oportunidad de trabajar en ese campo?

es el razonamiento que hace la informante ante la exigencia de experiencia cuando busca su primer empleo. El tempo del enunciado es muy lento y hay fuertes variaciones del fundamental.

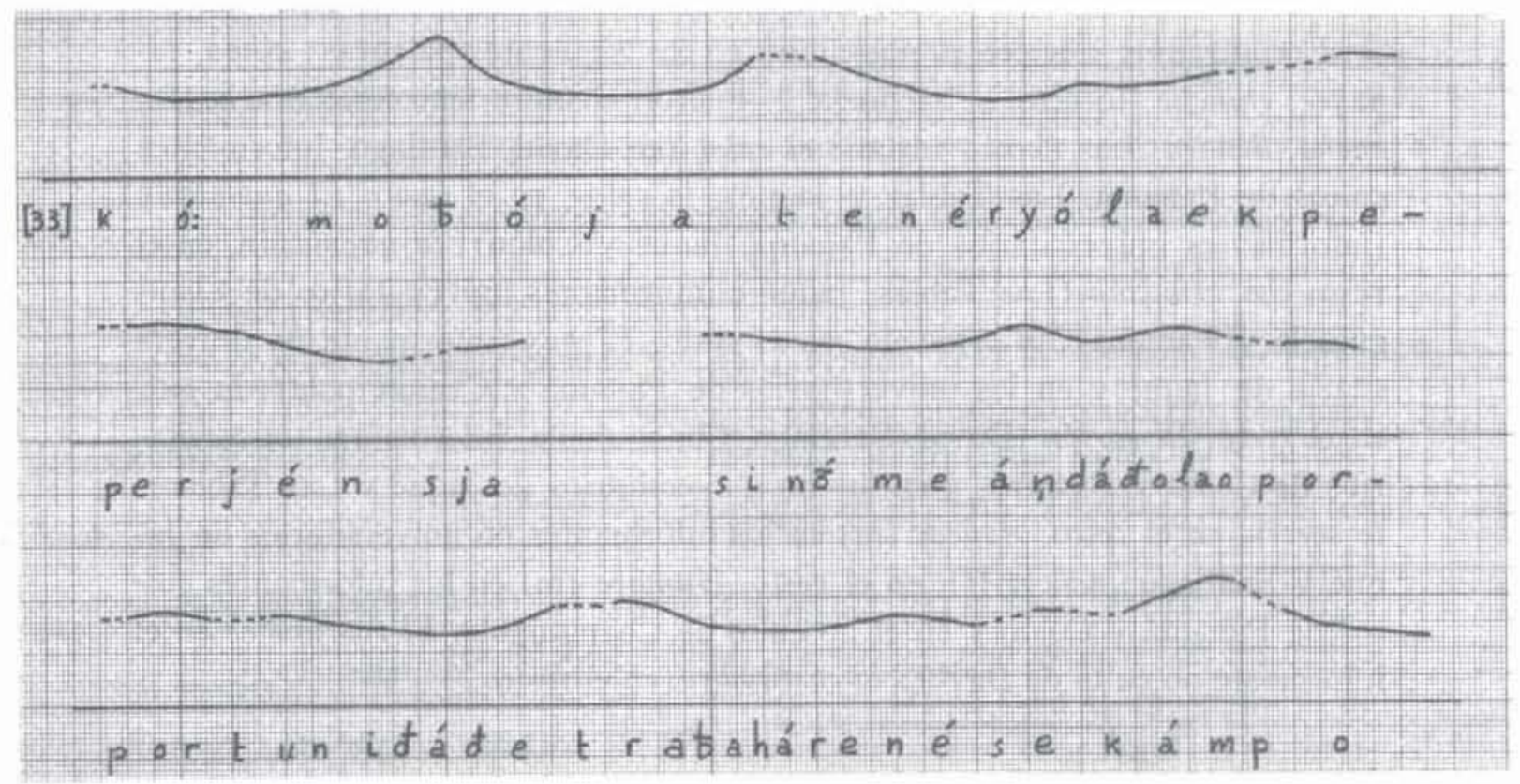

4. Morfosintaxis.

\subsection{Formación del plural.}

La formación del plural, en el caso de los sustantivos oxitonos, sigue las siguientes pautas:

a) -é / -é(s) ${ }^{28}$ : cafés, tes, etc., en todos los informantes, con la excepción de pieses en los informantes cultos de Colón, Jaqué, Santiago y en el universitario de Panamá ; cafeses también en este último.

b) -á / -ás: en todos los puntos, con excepción de un informante de Jaqué (papases, sofases) y el informante culto de Santiago (sofases). 
en los informantes no universitarios de Santiago y Jaqué; truenar, en el no universitario de Changuinola ${ }^{50}$.

Hay que señalar también aquí la diptongación en la vocal tónica de la tercera persona del plural del perfecto, y de la primera y tercera del singular del imperfecto de subjuntivo, por analogía con las mismas personas y tiempos de otros verbos de la misma conjugación : dijieron "dijeron", en los informantes no universitarios de Santiago, Las Tablas y Changuinola; trajieron "trajeron", en Changuinola, en el informe culto de Jaqué y en los no universitarios de Colón y Santiago; dijiera "dijera", en los informantes cultos de Changuinola y Jaqué, y en el no universitario de Santiago.

\subsubsection{Desinencias verbales.}

En las desinencias verbales, hay que señalar la tendencia a añadir /-s/ a la segunda persona del singular del pretérito perfecto, por analogía con la misma persona de los demás tiempos. El fenómeno es muy frecuente en español. En nuestras encuestas, hemos encontrado vinistes en Jaqué, en los informantes cultos de Changuinola, Santiago y Colón, y en el no universitario de David; en los demás informantes, viniste. Llegastes, en los informantes cultos de Changuinola, Colón, Santiago, Jaqué y en el no universitario de David; en el resto, llegaste. Trajistes, en los informantes universitarios de Changuinola, Colón y Jaqué, y en los no universitarios de Las Tablas y David; para los demás informantes es trajiste.

En general, predomina la forma normativa, $\sin /-\mathrm{s} /$.

\subsubsection{Pretéritos irregulares.}

Hemos encontrado en nuestras encuestas las siguientes formas de los pretéritos irregulares, por analogía con el infinitivo: maldeci, en un informante culto de Panamá y en los no universitarios de Jaqué, Las Tablas y Santiago; andé, en el informante no universitario de Panamá; cabimos, en el informante culto de Changuinola; deshacieron, en Jaqué y en los informantes no universitarios de Changuinola, Las Tablas y Santiago; manteni, en este último ${ }^{51}$.

Las formas arcaicas vide, vido, y truje, trujo, trujeron se mantienen aún

\footnotetext{
so Las formas normativas, más generales, son: cuezo, fuerzo, reviego, quiero, tuesta, truena, siembro, quiebra, aprieta, apretar, empedrar, enterrar, tronar.

${ }^{51}$ En el resto, siempre más generales, maldije, anduve, cupimos, detuvo (siempre), mantuve.
} 
en las zonas rurales de Santiago, David, Las Tablas y Jaqué, en las generaciones medias y viejas.

Hemos de señalar también que, en nuestras encuestas, sólo hemos encontrado Ayer venimos y Ayer veniste, en los informantes no universitarios de Changuinola, Panamá y Santiago; en los demás informantes, vinimos, viniste y salimos.

\subsubsection{Futuros y condicionales irregulares.}

En la formación de los futuros y condicionales irregulares, predomina el criterio normativo; son excepciones saliré y teneria, en el informante no universitario de Santiago; quedré, en el mismo y en el de Las Tablas; salirí, en los de Jaqué y Santiago. En el resto de los informantes, saldré ${ }^{52}$, pondré, querré, sabrá, tendría, saldría.

\subsubsection{Imperativos irregulares.}

Cuando el imperativo lleva algún pronombre enclítico, se sustituye, a veces, por la tercera persona del presente de indicativo: diceselo "diselo", en los informantes no universitarios de David y Jaqué, y en el culto de Changuinola; hácenos, en el mismo de Jaqué, quien también dijo pónelo, junto al culto de Changuinola y al no universitario de Santiago ${ }^{53}$.

\subsubsection{Formación de los participios irregulares.}

La formación de los participios irregulares responde, en general, a los criterios normativos. Con estar y con haber, hemos encontrado las siguientes formas incorrectas: abrido: informantes no universitarios de Jaqué y Colón: el resto, abierto; rompido: informantes no universitarios de Santiago, Jaqué y Changuinola; en el resto, roto; freido: informantes no universitarios de Santiago y Colón, y en los universitarios de Panamá y Jaqué; en el resto, frito; revolvido, escribido, deshacido, en los informantes no universitarios de Santiago y Changuinola; en el resto, revuelto, escrito, deshecho; maldito, en los informantes cultos de Jaqué, David y Panamá, y en los no universitarios de Colón y Las Tablas; maldecido, en los demás.

sa Muchos informantes alternan saldré con voy a salir.

53 En los demás informantes, dinos, diselo, haznos, ponlo. 


\subsubsection{Alternancia de prefijos.}

En los prefijos, podemos señalar: disvariar: informantes no universitarios de Santiago y Changuinola; destinguir: informantes no universitarios de Colón y Jaqué ; descomulgar: informantes no universitarios de Panamá, Jaqué, Changuinola, Santiago y Las Tablas; destornudar: informantes no universitarios de Colón, Jaqué, Santiago y Las Tablas. En el resto, las formas normativas despertar, desvariar, distinguir, desertar, excomulgar, estornudar.

\subsubsection{Sufijos derivativos "-ar", "-ear" para la formación verbal.}

Hay alternancia en el uso de uno u otro prefijo: tasajar: Colón, informantes cultos de Jaqué y David, y no universitario de Santiago; tasajear, en los demás; apuñalar, en David y en el informante culto de Colón; en el resto, apuñalear; desmadrar: Jaqué, informantes cultos de Panamá y Santiago, y en el no universitario de David; los demás, desmadrear; rumorear: en Changuinola e informantes no universitarios de David, Santiago, Las Tablas, Panamá y Colón; rumorar, en los demás.

\subsubsection{Empleo de "saber" como verlo modal.}

El uso de saber, como auxiliar, con el significado de 'soler' ("Sabia venir antes por aquí, pero ya hace tiempo que no viene”), del que hay testimonios grecolatinos, en el español del Siglo de Oro, en las lenguas románicas ${ }^{54}$, y que se conserva hoy en varias zonas de América, también aparece en $\mathrm{Pa}$ namá, aunque Kany ${ }^{55}$ no lo mencione: se da en Jaqué, Colón, Las Tablas, Santiago, Changuinola y en el informante no culto de David. No obtuvimos respuesta en Panamá ni en el informante culto de David.

\subsubsection{Empleo de "haber" en lugarde "ser"o "estar".}

El uso arcaico de haber por estar o ser ("Aquí habemos cuatro hombres"), no señalado por Kany para Panamá ${ }^{56}$, lo registramos en Jaqué, en

\footnotetext{
4 V. Marfa Rosa Lida de Malkiel, «Saber 'soler' en las lenguas romances y sus antecedentes grecolatinos», Ramance Pbilology, II, 1949, págs. 269-283.

Ss Op. cit., págs. 205-209.

So Op. cit., págs. 215-217.
} 
Informantes cultos de Panamá, de Changuinola, de Santiago y en los informantes no universitarios de Las Tablas y David; la mayoría de nuestros encuestados prefirió: "Aqui estamos cuatro hombres." Del mismo modo, es más general "Fuimos muchos los heridos" que "Hubimos muchos heridos", que sólo apareció en los informantes no universitarios de Jaqué, Panamá y Colón.

\subsubsection{Formas verbales arcaicas.}

De las formas arcaicas vide, vido, truje, trujo, trujieron, que aparecen en nuestro Cuestionario, las correspondientes a ver habían sido oídas a los ancianos en Jaqué, o eran usadas por los campesinos en Las Tablas, Santiago, David y Changuinola. Las formas correspondientes a traer se oyen aún a los ancianos de Jaqué, Santiago y Las Tablas. Ninguno de nuestros informantes las empleaba.

\subsubsection{3. "Haber" $y$ "hacer" como impersonales.}

Haber y hacer, como impersonales, ofrecen el siguiente comportamiento en nuestro país: "Habia dos árboles": informantes cultos de Santiago y $\mathrm{Pa}$ namá; en el resto, habian ${ }^{57}$. "Hubieron fiestas", en Jaqué, Colón, en la clase social baja de David y en un informante culto de Panamá; en el resto, hubo. "Hace seis años que no te veo": Jaqué, Panamá, David e informantes cultos de Las Tablas y Santiago; en el resto, hacen ${ }^{58}$.

\subsubsection{Uso del pretérito simple o del compuesto.}

En nuestras encuestas, aparece una clara preferencia por el empleo del pretérito simple 59 : "Ayer volvimos temprano", general, frente a hemos vuelto, sólo en dos informantes; "Anoche llegó mi hermano" o "Esta tarde pasé por su casa", generales, frente a ha llegado o ha pasado, en el mismo informante.

s7 Kany, op. cit., pág. 214, señala este fenómeno para Panamá, citando a Ignacio Herrero Fuentes, «El castellano en Panamá», Universidad: Revista de la Universidad Interamericana (Panamá), XXII, 1944, págs. 81-101.

s8 Señalado también por Kany, op. cit., pág. 217.

69 Fenómeno registrado también por Kany para Panamá, op. cit., pág. 163. 


\subsubsection{Uso del condicional por el imperfecto de subjuntivo.}

En nuestros materiales, se prefiere el uso del imperfecto de subjuntivo: "Si tuviera tiempo, iría." Sólo un informante utilizó el condicional.

\subsubsection{Uso del infinitivo o del gerundio como elemento inicial de accio- nes consecutivas.}

Nuestros informantes utilizaron el infinitivo: "Al llegar, escribiremos", "Al acabar de comer, daremos un paseo". Sólo un informante de Jaqué prefirió "En acabando de comer".

\subsubsection{Alternancia "hemos/habemos" en el pretérito compuesto.}

La forma general en el español de Panamá es hemos: "No lo hemos visto todavía", con la excepción del informante no universitario de Santiago que respondió "No lo habemos visto todavía".

\subsubsection{Confusión entre las terminaciones "-mos" $y$ "-nos".}

En las encuestas sistemáticas, prácticamente no se produjo confusión entre las mencionadas terminaciones. Las formas incorrectas estábanos, andábanos, vénganos aparecieron sólo en los informantes no universitarios de Santiago y Jaqué. No obstante, el fenómeno es muy frecuente en todo el país, sobre todo en Panamá, en Colón y en las Provincias Centrales: es corriente oír íbanos, veníanos, etc.

\subsubsection{Voseo verbal.}

Las noticias que poseíamos sobre la existencia y extensión del voseo en Panamá eran algo confusas y contradictorias. Para estudiarlo, recorrimos todo el país. Los resultados que, pormenorizados, hemos publicado en un reciente artículo ${ }^{\infty}$, son los siguientes: el voseo pervive en las provincias de

\footnotetext{
80 Antonio Quilis y Matilde Graell, «El voseo en Panamá», Revista de Filologia Es. pañola, LXIX, 1989, págs. 173-178.

V. también Kany, op. cit., pág. 81, y Robe, op. cit., págs. 128-133.
} 
Herrera, donde en ciertas zonas alterna con el $t \dot{u}$; de Los Santos, con mucho arraigo (lo emplea la población joven); de Veraguas, y en parte de la provincia de Coclé.

El voseo está fuertemente estigmatizado en Panamá : la sociedad lo considera como rasgo rústico y lo reprueba. La escuela lo corrige tenazmente. Pese a todo, en el territorio indicado, se conserva bastante bien, aunque con cruces, a veces, entre tiempos y personas.

Las formas encontradas fueron las siguientes:

1. Presente de indicativo:

$\begin{array}{lll}\text { Vos cantái(s) } & \text { Vos coméi(s) } & \text { Vos segui(s) } \\ \text { Tú cantái(s) } & \text { Tú coméi(s) } & \text { Tú segui(s) } \\ \text { Tú canta(s) } & \text { Tú come(s) } & \text { Tú sigue(s). }\end{array}$

Es corriente oír: “¿Tú cómo estái?”, “¿Vos cómo estái?”, “¿Cuándo queréi que venga?”, "Tú queréi hacerlo", "Tú podéi saltar".

2. Imperfecto de indicativo:

$\begin{array}{lll}\text { Vos cantaba(s) } & \text { Vos comia(s) } & \text { Vos seguia(s) } \\ \text { Tú cantaba(s) } & \text { Tú comía(s) } & \text { Tú seguia(s). }\end{array}$

3. Pretérito de indicativo:

$\begin{array}{lll}\text { Vos cantaste } & \text { Vos comiste } & \text { Vos seguiste } \\ \text { Tú cantaste } & \text { Tú comiste } & \text { Tú seguiste. }\end{array}$

4. Futuro de indicativo:

$\begin{array}{lll}\text { Vos cantará(s) } & \text { Vos comerá(s) } & \text { Vos seguirá(s) } \\ \text { Tú cantará(s) } & \text { Tú comerá(s) } & \text { Tú seguirá(s). }\end{array}$

También hemos recogido formas como: Vos cantaréi(s), Vos comeréi(s), Vos seguiréi(s).

Es muy frecuente sustituir la forma de futuro por una perífrasis: Vos vai(s) a cantar. 
5. Presente de subjuntivo:

$\begin{array}{lll}\text { Vos cante(s) } & \text { Vos coma(s) } & \text { Vos siga(s) } \\ \text { Tú cante(s) } & \text { Tú coma(s) } & \text { Tú siga(s) } \\ \text { Vos cantéi(s) } & \text { Vos comái(s) } & \text { Vos sigái(s) } \\ \text { Tú cantéi(s) } & \text { Tú comái(s) } & \text { Tú sigái(s). }\end{array}$

6. Imperfecto de subjuntivo:

$\begin{array}{lll}\text { Vos cantara(s) } & \text { Vos comiera(s) } & \text { Vos siguiera(s) } \\ \text { Tú cantara(s) } & \text { Tú comiera(s) } & \text { Tú siguiera(s). }\end{array}$

7. Imperativo:

$\begin{array}{lll}\text { Canta } & \text { Come } & \text { Sigue } \\ \text { Cantá } & \text { Comé } & \text { Segui. }\end{array}$

Verbo "ser". Hemos encontrado las siguientes formas:

$\begin{array}{llll}\begin{array}{l}\text { Vos so(s) } \\ \text { Tú so(s) }\end{array} & \text { Vos soi(s) } & \text { Vos sei(s) } & \\ \text { Tó soi(s) } & \text { Tú sei(s). } & \\ \begin{array}{l}\text { Tú ere(s) } \\ \text { Vos era(s) }\end{array} & & \\ \text { Tó fuiste } & \text { Vos será(s) } & \text { Vos sea(s) } & \text { Sé vo(s) } \\ \text { Tú fuiste } & \text { Tú será(s) } & \text { Tú sea(s) } & \text { Sé tú. }\end{array}$

Verbo "haber". Vos, tú ha(s). Vos tú habéi(s). Vos, tú hubiste.

\subsection{Adverbio.}

\subsubsection{Concordancia del adverbio "medio".}

$\mathrm{El}$ adverbio medio no debe concordar con el adjetivo porque es invariable. Ya Bello comentaba: "En Chile se emplea mal el adjetivo por el adverbio, diciendo, por ejemplo, La niña salió media desnuda; Quedaron medios muertos" "61. El fenómeno, muy extendido por América, también aparece en Canarias y en Madrid ${ }^{62}$. Kany no señala el fenómeno en Panamá ${ }^{63}$, donde se da abundantemente:

-1 Gramática de la Lengua castellana destinada al uso de los americanos. Ed. de Ramón Trujillo, Tenerife, 1981, pág. 298.

${ }_{62}$ Antonio Quilis, La concordancia gramatical en la Lengua española bablada en Madrid, Madrid, C. S. I. C., pág. 36.

os Op. cit., págs. 34-36. 
- Mis hermanos son medios tontos: En los informantes no universitarios de Jaqué, David, Santiago, Changuinola y en el universitario de Colón; medio tontos, en el resto.

- Mis hermanas son medio tontas: en los universitarios de Panamá, Santiago y en el no universitario de David; media tontas, en el no universitario de Colón; medias tontas, en el resto.

- Mi hermana es medio tonta: en el universitario de Santiago y en el no universitario de David; media tonta, en el resto.

\subsubsection{Colocación de "más" en secuencias con pronombres o adverbios.}

En el español general, el orden de palabras en secuencias como nada más, nadie más, ninguno más, nunca más, puede invertirse y realizarse como más nada, más nadie, más ninguno y más nunca; este fenómeno aparece tanto en España (León, Galicia y Aragón) ${ }^{64}$, como en Hispanoamérica (Argentina, Uruguay, Colombia, Venezuela, Costa Rica, Cuba, Puerto Rico, República Dominicana, Méjico).

En nuestras encuestas, el resultado fue el siguiente:

- más nada, en Panamá, Jaqué, Colón, David, Las Tablas y Santiago; nada más, en Changuinola.

- más nunca, en Panamá, David, Las Tablas e informantes universitarios de Jaqué, Santiago y Changuinola; en el resto, nunca más.

- más nadie, en Panamá, Jaqué, Colón, Las Tablas e informante culto de David; nadie más, en Changuinola, David, Santiago e informante universitario de Panamá.

- más ninguno, en Jaqué, Las Tablas e informante universitario de $\mathrm{Pa}$ namá; ninguno más, en el resto.

\subsection{Preposición.}

4.6.1. Uso de "para" o "por" con complemento de interés.

En nuestras encuestas, las soluciones son muy diferentes: Trabajaba por mantenerse, sólo en los informantes no universitarios de David, Changuinola y Las Tablas. Trabajaba para mantenerse, en el resto. Hizo lo posible para

at V. Manuel Alvar, El habla del Campo de Jaca, Salamanca, C. S. I. C., 1948, pág. 117; Kany, op. cit., págs. 309-310, y Alonso Zamora Vicente, Dialectología española, Madrid, Gredos, 1967, pág. 429. 
encontrar el libro, en los informantes universitarios de Panamá, Colón y Jaqué, y en el no universitario de David; en el resto, Hizo lo posible por encontrar el libro.

\subsubsection{Construcciones con o $\sin$ "de" ante infinitivo complementario.}

Nuestro Cuestionario contiene dos preguntas sobre este punto. Las soluciones son muy desiguales: Hace de reir, en los informantes no universitarios de Las Tablas y Changuinola; Hace reir, en el resto. Hacerse de rogar, en Panamá, David, informantes no universitarios de Jaqué y Changuinola, y en el culto de Santiago ; Hacerse rogar, en Panamá, Colón, informantes universitarios de Las Tablas, Jaqué y Changuinola, y en el no universitario de Changuinola.

\subsubsection{Preferencia por " $a$ " o por "en" con verbos de movimiento.}

El español europeo prefiere el uso de entrar en ${ }^{65}$, mientras que en el español de América, el empleo de $a$ es la regla general en este caso. El español antiguo, desde el Cid, también conoce el uso con $a$ : en el Poema de mío Çid: "Entrando $a$ Burgos."

En nuestras encuestas, fueron generales las respuestas Entrar a la iglesia e Ir a casa del médico.

\subsubsection{Uso preferente de "por causa de" o de "a causa de".}

Nuestro Cuestionario contiene dos preguntas sobre este punto, cuyas respuestas han sido desiguales en nuestro dominio lingüístico: "No se veía por causa del humo" fue la respuesta en Panamá, en los informantes no universirios de Colón, Santiago y Las Tablas, y en los universitarios de Jaqué y David; en el resto, a causa de. "Dejaron de trabajar por causa de la lluvia", en David, Las Tablas, Panamá, informante universitario de Jaqué y en el no universitario de Colón; a causa de, en los demás.

es Según Kany, op. cit., pág. 340 - citando a Espinosa, Cuentos populares españoles-, entrar a se registra en Segovia, Madrid, Ciudad Real, Sevilla, Granada y Jaén. 


\subsubsection{Significado en la secuencia "hasta + expresión de tiempo".}

Este tipo de sintagmas ha dado en nuestras encuestas los siguientes datos:

- Abren hasta las once, con el significado de 'cierran a las once', en todos los informantes, menos en los no universitarios de Santiago y Changuinola; para ellos, es 'abren a las once'.

- Trabajan hasta las doce: para todos los informantes: 'terminan de trabajar a las doce'.

- Viene hasta las once, con el significado de 'a las once se va', en Jaqué, Santiago y en los informantes no universitarios de Panamá y Las Tablas. En el resto de los informantes, tiene el significado de 'llega a las once'.

- Lo esperan hasta mañana, con el significado de 'mañana dejarán de esperarlo' aparece sólo en los informantes universitarios de Panamá y Colón, y en los no universitarios de David y Jaqué. Para el resto de los encuestados, tiene el significado de 'creen que mañana llegará'.

- Pagan hasta mañana, con el significado de 'mañana dejarán de pagar', en Las Tablas, en el informante no universitario de Jaqué y en el universitario de Santiago. En el resto, significa que 'mañana comienzan a pagar'.

- Hasta mañana pagan, con el significado de 'mañana empiezan a pagar', en Panamá y Colón; en el resto, 'mañana terminan de pagar'.

\section{Léxico.}

Las encuestas han proporcionado un léxico abundante y variado. En las páginas que siguen, ofrecemos sólo una muestra de él. Muchas palabras no han sido recogidas por los repertorios de panameñismos ${ }^{66}$; otras aparecen sin indicar la procedencia geográfica; hay también un grupo numeroso que en nuestras encuestas ha aparecido con un significado distinto, etc. No incluimos, lógicamente, las palabras que son generales en el país y no tienen, al parecer, sinónimos en el léxico activo de los hablantes, como recámara 'dormitorio', pluma 'grifo', tusa 'zuro', brusca 'partícula de alguna sustancia que flota en el aire', chicheme 'bebida preparada con maíz hervido sin mo-

66 Las siglas responden a las siguientes obras:

ARP: Angel Revilla, Panameñismos, Panamá, 1976.

BIC: Baltasar Isaza Calderón, Panameñismos, Panamá, Academia Panameña de la Lengua, 1968.

MAM: Marcos A. Morfnigo, Dicciomario de americanismos, Barcelona, Muchnik Editores, 1985. 
ler', etc.; ni casos como cuchilla 'navaja' frente a navaja o barbera 'navaja de afeitar', alfiler 'imperdible' y alfiler de cabeza 'alfiler', etc.

Veamos algunos ejemplos:

Afilador (D, S, T, P, J), amolador (C, Ch, T), afiladero (C), filero (Ch).

Afilar (general), amolar (C, D, S, P), dar el filo (D), filar (Ch), molar (T). Afilar, piedra de (C, Ch, J, P, S,), piedra de amolar (C, D, P, S), piedra de molar (Ch), esmeril y meril $(\mathrm{T})$.

Albino 'camarón' (T).

Ananse 'araña' (J).

Andadera 'andador de los niños' (general), corredera (T), rodaja (D).

Antaño (D, J, S, P; en Ch y T, la utilizan los ancianos), años atrás (T), tiempos atrases $(\mathrm{J})$, en aquel tiempo $(\mathrm{S})$, tiempo atrás $(\mathrm{P})$, hace muchos años (P), tiempo pasado (T), Tiempo de ñampa (C; ñmpa < quichua "ñaupa" 'antiguo', según MAM, quien lo cita para Argentina y Ecuador, "En tiempo de ñaupa", 'En tiempo de Maricastaña'; BIC da el mismo significado, pero una procedencia equivocada del término).

Armario 'armario empotrado' (P), closet (C, Ch, D, J, P, S, T; MAM lo registra para América), ropero $(\mathrm{D}, \mathrm{J}, \mathrm{P}, \mathrm{T})$, estante $(\mathrm{J}, \mathrm{P})$.

Armario 'mueble, generalmente de madera' $(\mathrm{C}, \mathrm{Ch})$, chifonier $(<\mathrm{fr}$. chiffonnier", D; BIC, con otro significado), ropero $(\mathrm{S})$, estante $(\mathrm{C}, \mathrm{Ch}, \mathrm{D}, \mathrm{J}$, $\mathrm{S}, \mathrm{T})$.

Atajo (Ch, D, P, S), chascot (< ingl. "short cut"; C), trillo (T), trocha (C, $\mathrm{Ch}, \mathrm{J}, \mathrm{P}, \mathrm{T})$, trochita $(\mathrm{P})$.

Avaro 'id.' (J), miserable (P), truñuño (D), tacaño (P, Ch), duro (general), casasola (T), mezquino (S, T), egoista (C, J, P).

Barrenador 'ciervo volátil' (D), escarabajo (D, J, P, T), culilargo (T), cucarrón (J), cocorrón (C).

Batería 'apuntaciones fraudulentas para los exámenes' (general), pila (C, P). Bebeagua 'avispa' (T).

Bifurcación de caminos (P), cruce $(\mathrm{C}, \mathrm{Ch}, \mathrm{D}, \mathrm{S}, \mathrm{T})$, desviación $(\mathrm{C})$, divisorio $(\mathrm{J})$, encuentro $(\mathrm{S})$, intersección $(\mathrm{Ch}),[\mathrm{i}] i(\mathrm{D})$, ramal $(\mathrm{J})$, ye $(\mathrm{D}, \mathrm{T})$.

Bocacho 'desdentado' (general; 'id', en BIC), gacho (D), desbocachado (C).

Boligrafo (D, P, S), pluma (general), lapicero (P), estilógrafo (J).

Botánico 'persona que cura con hierbas' (C, P).

Bulla 'ruido' (P).

Caballito del diablo 'libélula' (C, Ch, D, J, P, S, T; MAM lo señala en Argentina y Méjico), achicapozos $(\mathrm{J})$, caballito $(\mathrm{Ch}, \mathrm{D}, \mathrm{P}, \mathrm{S}, \mathrm{T})$, diablito (C), helicóptero $(\mathrm{J})$.

Caballito 'pídola' (D, P), brincar caballito (C), mula (J), salto montar $(\mathrm{T})$, sapito (C). 
Cabello rizado $(\mathrm{P})$, afro $(\mathrm{Ch})$, crespo $(\mathrm{C}, \mathrm{D}, \mathrm{J})$, churrusco $(\mathrm{D}, \mathrm{S}$; 'id', en ARP y BIC), duro (J, P), grifo (S, T), ondulado (C), pelo de chombo $(\mathrm{Ch}, \mathrm{D})$, pelo duro $(\mathrm{P})$, pelo rizo $(\mathrm{T})$, rizo $(\mathrm{S})$.

Camote (Ch, D, J, P, S ; 'id', en BIC), batata (C, T), papa dulce (Ch), patata (D).

Celaje (D, P, S, T), arrebol (J), celajes del sol (C), crepúsculos $(\mathrm{Ch}, \mathrm{J})$, el sol de los muertos (C).

Cigarra 'saltamontes' (D), chapul (J), chigarra (S), grillo (C, P, S, T), saltamontes (Ch, T).

Coa (general) 'palo largo, con un hierrecito en la punta, que sirve para hacer agujeros en la tierra'; del arauaco antillano, coa, según MAM, quien lo localiza en Cuba y en Méjico; también en ARP y BIC.

Cocotero (D, J), palma (C, Ch, D, P, T), palma de coco (D, J, S), palo de coco $(\mathrm{Ch})$, palmera $(\mathrm{P})$.

Colibri (D), chupaflor (J), picaflor (C, Ch, P, T), visitaflor (C, Ch, D, J, P, $\mathrm{S}, \mathrm{T}$; 'id', en ARP y BIC).

Columpio (D, P, S), mecedora $(\mathrm{S})$, sinchuán $(\mathrm{Ch})$, sinsuán $(\mathrm{C}, \mathrm{J}, \mathrm{P})$, suinsuán (Ch; estos tres últimos proceden del inglés "swing"), trapecio (D, $\mathrm{S}, \mathrm{T})$, tintibajo (D).

Combamba 'barbilla' (J).

Cometa (general). Las más grandes reciben los nombres de pandero (J, P, $\mathrm{S}, \mathrm{T}$; 'id' en ARP y BIC), papalote (D, P; del náhuatl "papalotl"; MAM lo señala en Méjico y en las Antillas), paneta (S). Más pequeñas son: biruli (C, porque se construye con el biruli 'cañecilla de la punta de la caña de azúcar, donde salen las flores') y gallinazo (P).

Conejo silvestre $(\mathrm{S}, \mathrm{P})$, conejo de monte $(\mathrm{C}, \mathrm{Ch}, \mathrm{D}, \mathrm{J}, \mathrm{P})$, conejo $(\mathrm{C}, \mathrm{P}$, $\mathrm{T})$, conejo pintado $(\mathrm{J}, \mathrm{S})$, guagua $(\mathrm{J}$; en Colombia, según MAM, recibe este nombre un roedor), machango $(\mathrm{S}, \mathrm{T})$, muleto $(\mathrm{P}, \mathrm{S}$; 'id' en BIC y en $\mathrm{ARP})^{67}$, quinco (S).

Corneto 'estevado' (D, S), combo (S), cumbo (Ch, D), curveto (T), curvo (C, J, T, P).

Cortarse el pelo (C, Ch, D, P, S, T), barbear $(\mathrm{Ch})$, hacerse el corte $(\mathrm{S})$, motilarse $(\mathrm{C}, \mathrm{J}, \mathrm{T})$, pelarse $(\mathrm{T})$, peluquear $(\mathrm{J})$, peluquearse $(\mathrm{S})$, recortar $(\mathrm{J}$, $\mathrm{P})$, tusar (S).

Cuclillas, ponerse en $(\mathrm{Ch}, \mathrm{J}, \mathrm{P})$, agacharse $(\mathrm{C})$, añongotarse $(\mathrm{J}, \mathrm{T}$; “añingotar(se)" : en ADP, 'agacharse'; en BIC, 'ponerse en cuclillas'), de cuclillas $(\mathrm{Ch})$, ñangotarse $(\mathrm{T})$.

Cuco 'coco, fantasma' (Ch, D, J, P, S, T), coco (P), cucu (C), cucumán (C), duende (C), tulivieja (C; 'id', en BIC y en ARP).

67 Conejo muleto 'liebre' (C). 
Cucuyo 'insecto fosforescente terrestre' (general ; 'id', en ARP), lusiema (S), alumbraculo (J).

Cuello 'cadena que se lleva en el cuello' (D).

Cuestas, llevar a (P), a caballo (Ch), a guachinche (C, D, P, S, T), a guachincha (Ch), a mono (D), a pago $(\mathrm{J})$.

Curumbita 'cima de un monte' ${ }^{\&}$ (D, P; 'id', en ARP), cima (C, Ch), cuchilla $(\mathrm{J})$, pico $(\mathrm{C}, \mathrm{Ch}, \mathrm{J})$.

Cutarra 'especie de sandalia rústica, con suela de goma' es calzado típico del campesino (C, D, P, S, T); 'id', en MAM, BIC, ARP).

Chauala 'especie de alpargata de tela con tacón' (S).

Chérigo 'tuerto' (C).

Chitra 'jején' (Ch, D, P, S, T; 'id', en ARP y BIC), jején (C, J), ején (C; 'id', en ARP).

Churudo 'arroz con cáscara' (Ch), churú (Ch, D, J, P, S, T; 'id', en ARP), chiru (C), bañisco $(\mathrm{J})$, afrecho (Ch), soldado (C, J; 'id', en ARP).

Chuzo 'palo terminado en punta que se utiliza para sembrar' (D, J, S, T); también sembrar a chuzo (S).

Dedo 'cada plátano que sale del gajo del racimo' (Ch).

Diarrea $(\mathrm{C}, \mathrm{Ch}, \mathrm{J})$, churria (J, T; 'id' en BIC y ARP; MAM lo señala en Colombia, Guatemala y R. Dominicana), obradera (Ch, T; 'id', en MAM, ARP y BIC).

Enaguas (D, S, en el campo) ${ }^{69}$, faldita (D, T), faldita peticote (< ingl. "petticoat"; C, Ch, J, P, S, T; 'id', en ARP y BIC), pericote (P), mediofondo (C).

Escampar 'guarecerse de la lluvia' ( ${ }^{70}$; MAM no lo da para Panamá $\left.{ }^{71}\right)$, aguarecerse y guarecerse $(\mathrm{C})$, refugiarse $(\mathrm{Ch})$.

Escarabajo 'id' (Ch, J), corrococo $(\mathrm{T})$, gorgojo $(\mathrm{P})$, cocorrón $(\mathrm{C}, \mathrm{P})$, cucarrón $(\mathrm{J})$, abejón $(\mathrm{P})$.

Fusil 'relámpago' (D, J, S; 'id', en ARP), relámpago (C, Ch), fusilaje (Ch). Fusilazo 'rayo' (T), fusil (Ch), rayo (C, Ch, J), candela (C).

Fusilear 'relampaguear' (D, S ; 'id', en ARP), relampaguear (C, Ch, J).

Gacho 'falto de un diente' $(\mathrm{P})$, ventana $(\mathrm{J})$, desbocachado $(\mathrm{C})$, bocacho $(\mathrm{C})$. Gajo 'cada mano de plátanos que sale del racimo' (Ch).

Gandio 'glotón' (D), comeón (D), comelón (C, Ch, J, S, T), comilón (T), glotón $(\mathrm{C}, \mathrm{Ch}, \mathrm{P}, \mathrm{S})$, gotón $(\mathrm{T})$, goloso $(\mathrm{C}, \mathrm{P})$, jartón $(\mathrm{S}, \mathrm{T})$, hartón $(\mathrm{J}$, $\mathrm{P}$; 'id', en $\mathrm{BIC})$, hambriento (P).

68 También la 'parte más alta de cualquier cosa'; 'id' en BIC.

69 Nagua, antiguamente, 'falda larga' (D).

70 En este punto, también tiene el significado de 'cesar la lluvia'.

71 Nosotros la hemos encontrado con el mismo significado en Cuba, Ecuador y en Costa Rica (San Rafael de Guatuso y Santa Cruz). 
Garabato 'palo torcido en un extremo que se emplea para tapar el grano de maiz que se ha sembrado' (C).

Garganta (general), galillo (D, S), guagüero $(\mathrm{J})$, güergüero $(\mathrm{D}, \mathrm{P}, \mathrm{T})^{72}$.

Garnatada (C, D, J; 'id', en BIC), gasnatada (P), bofetada (P), cachetada $(\mathrm{C}, \mathrm{D}, \mathrm{P}, \mathrm{S}, \mathrm{T})$, carnatada $(\mathrm{C}, \mathrm{J})$, palmada $(\mathrm{P})$.

Gavilán (C, Ch, D, J, P), gavilán pollero (Ch, P), cao (D), pollero (D, P, S), come pollos $(\mathrm{T})$, pájaro pollero $(\mathrm{S}, \mathrm{T})$, quiscuí $(\mathrm{T})$.

Golondrino $(\mathrm{Ch})$, golondrina $(\mathrm{S}, \mathrm{P})$, nacido $(\mathrm{C}, \mathrm{Ch}, \mathrm{D}, \mathrm{J}, \mathrm{P}, \mathrm{S}, \mathrm{T})$, nacido ciego $(\mathrm{T})$, seca $(\mathrm{Ch})$.

Guáguaras 'hormigas grandes de color chocolate' (S).

Guiñar el ojo (T), guiñar (C, D, J, P), griñar (C), hacer ojitos (S), ojito (T), quiñar el ojo (Ch, P, S).

Hombro, llevar a (D), en hombro (S), a bochinche (C), a guachinche (C, D, $\mathrm{J}, \mathrm{P}, \mathrm{S})$, cargado $(\mathrm{T})$, cargado en hombros $(\mathrm{T})$, a caballo $(\mathrm{Ch}, \mathrm{P})$, a caballito $(\mathrm{C})$, a mochinche $(\mathrm{Ch})$.

Ingle $(\mathrm{Ch}, \mathrm{D}, \mathrm{J}, \mathrm{P}, \mathrm{S}, \mathrm{T})$, verija $(\mathrm{Ch}, \mathrm{D}, \mathrm{S}, \mathrm{T})$, bisagra (S, popular), entrepierna $(\mathrm{C}, \mathrm{Ch}, \mathrm{J}, \mathrm{P}, \mathrm{T})$.

Jugo 'liquido contenido en un fruto' (general).

Junta 'azofra' (Ch, D, J, P, S, T; 'id', en ARP y en BIC. Junta de embarre, por ejemplo, es la que se reúne para hacer casas), fajina (C), ayuda comunitaria $(\mathrm{P})$, ayuda comunal $(\mathrm{C})$, ayuda voluntaria $(\mathrm{Ch})$, cooperación (J), trabajo comunal (P).

Langosta $(\mathrm{C}, \mathrm{Ch}, \mathrm{D}, \mathrm{J}, \mathrm{P}, \mathrm{S})$, grillo $(\mathrm{C}, \mathrm{P}, \mathrm{S}, \mathrm{T})$, grillo veranero $(\mathrm{T})$, chigarra $(\mathrm{Ch})$.

Limonero $(\mathrm{C}, \mathrm{Ch}, \mathrm{D}, \mathrm{S}, \mathrm{T})$, árbol de limón $(\mathrm{P})$, limón $(\mathrm{P})$, palo de limón (general).

Luciérnaga 'insecto fosforescente volador' (C, Ch, D, J, P, T), cocuyo (S), cucuyo $(\mathrm{J})$, luciérnega $(\mathrm{S})$, lucema $(\mathrm{T})$, lucerito $(\mathrm{Ch})$.

Mancuernas 'gemelos de la camisa' (C, D, J, P, S, T), broches $(\mathrm{Ch})$, prendedores (Ch), ganchos (D).

Manzana 'nuez' (general), mansiya (T), güegüero (C), bocado de Adán (Ch).

Manzano (T), manzanero $(\mathrm{S})$, árbol de manzana $(\mathrm{P})$, palo de manzana $(\mathrm{C}$, D, J, P, S).

Mata 'arbusto' (C, P, T), árbol chico (C), arbusto (Ch, J, P).

Mogote 'elevación de terreno de unos dos metros de altura' (C, T); 'islotes de roca en la mar' (C).

Mono 'vestido enterizo que usan los mecánicos' $(\mathrm{S})$, buzo $(\mathrm{P})$, mameluco $(\mathrm{P}$, $\mathrm{J})$, overol (T, S, P, J, C, Ch), overón (D), saco (T).

n Gorgüero 'garganta de los animales' (T); güergüero 'papada' (S). 
Mono perezoso (C, Ch, J, P); 'id', en ARP), mono carillo (T), perico ligero $(\mathrm{J}$; 'id', en ARP), pericote $(\mathrm{C})$, perezoso $(\mathrm{C}, \mathrm{Ch})$.

Nacido 'antrax' (C, Ch, D, J, P, S, T), quiste (T), seca (P), tórzalo $(\mathrm{Ch})$.

Naranjo (D, P, T), árbol de naranja $(\mathrm{P})$, naranjero $(\mathrm{S})$, naranjal $(\mathrm{Ch})$, palo de naranja (general), palo de naranjo $(\mathrm{P})$.

Nata 'nariz pequeña, chata' (general).

Oso hormiguero (C, Ch, J; 'id', en ARP), oso chaqueta (J), gato hormigo (C, T).

Palo 'para designar a cualquier árbol frutal': palo de limón, de naranja, etc.

Panti 'bragas' (general), pantis (S), blúmer (antes, en S), calzonario ('id', en ARP y en BIC; las ancianas, en T; rural, en S).

Patuleco 'zambo' (C, S), contrecho $(\mathrm{J})$, dos pies zurdos $(\mathrm{Ch})$, gambado $(\mathrm{P})$, pando $(\mathrm{Ch})$, patillado $(\mathrm{T})$, pingüino $(\mathrm{J})$, virao $(\mathrm{S})$.

Pavearse 'faltar a clase voluntariamente' (general; 'id', en ARP y en BIC), fugarse $(\mathrm{J}, \mathrm{P})^{73}$.

Pelota 'joroba' (S), petaca (C ; 'id', en ARP y en BIC), tucupéi (J), cutumpés $(\mathrm{J})$.

Peral (C, S, T), palo de pera (C, D, J, P, S).

Peticote 'prenda interior femenina: especie de enaguas de cuerpo entero' (D, $\mathrm{S}, \mathrm{T})$.

Pita 'agave' (Ch, D, J, P, S), cabuya (T), cactus (C, P), henequén (S), piñuela $(\mathrm{T})$.

Palangana (P), aguamanil (C, P, S), lavamanos (J, S), platina (C), platón (Ch, D, S, T), porcelana $(\mathrm{J})$, tina $(\mathrm{Ch})$.

Pluma 'pluma estilográfica' $(\mathrm{D}, \mathrm{P}, \mathrm{T})$, pluma de tinta $(\mathrm{C}, \mathrm{S})$, pluma fuente $(\mathrm{C}, \mathrm{Ch}, \mathrm{D}, \mathrm{J}, \mathrm{P})$, pluma de fuente $(\mathrm{P})$, plumario $(\mathrm{J}, \mathrm{S}, \mathrm{T})$, plumero $(\mathrm{Ch})$.

Puerco saino 'cerdo salvaje' $(\mathrm{D}, \mathrm{P})$, puerco de monte $(\mathrm{C}, \mathrm{J}, \mathrm{T})$, puerco cimarrón $(\mathrm{S})$, puerco alzado $(\mathrm{J})$, puerco remontado $(\mathrm{J})$, macho de monte (P).

Quicio 1. 'escaloncito a la entrada de una puerta' (Ch, D, J, P, S). 2. 'rodapié' $(\mathrm{P}, \mathrm{T})$.

Rocio (Ch, D, P, S, T), sereno (general).

Sapito 'renacuajo' (D), guarisapo (J), gusarapo (D, P, S), pichoncito (T), ranita $(\mathrm{P})$, renacuajo $(\mathrm{C}, \mathrm{Ch}, \mathrm{P}, \mathrm{S}, \mathrm{T})$.

Tablero 'pizarra' (general), pizarrón (C, D, J).

Talingo 'cuervo' (S, P), cuervo (D, J, P), tordito (T), chango (T), llamamuertos (C).

Tallo 'planta del plátano o del guineo' (general), plátana (D), mata (J), guinea (D), platanera $(\mathrm{T})$.

73 Paveón 'el que se pavea' (D, T). 
Tartamudo (C, P, S, T), gago (general; 'id', en BIC), garigay (D), medialengua $(\mathrm{T})$.

Tobillo (C, Ch, D, J, S, P, T), torito (D), codo del pie (T), chocosuela (J).

Zumo 'jugo de la cáscara de un fruto' (general; MAM no lo señala en $\mathrm{Pa}$ namá). 